OPEN ACCESS

Edited by:

Yi Ma,

University of Connecticut, USA

Reviewed by:

Jianfeng $L i$

Sun Yat-sen University, China

Xiaofeng Wang,

Northwest A\&F University, China Honghui Lin,

Sichuan University, China

${ }^{*}$ Correspondence:

Kai He

hekai@lzu.edu.cn

Specialty section:

This article was submitted to

Plant Traffic and Transport,

a section of the journal

Frontiers in Plant Science

Received: 01 March 2017

Accepted: 06 April 2017

Published: 25 April 2017

Citation:

Gao Y, Wu Y, Du J, Zhan Y, Sun D,

Zhao J, Zhang S, Li J and He K (2017) Both Light-Induced SA Accumulation and ETI Mediators Contribute to the

Cell Death Regulated by BAK1 and BKK1. Front. Plant Sci. 8:622 doi: 10.3389/fpls.2017.00622

\section{Both Light-Induced SA Accumulation and ETI Mediators Contribute to the Cell Death Regulated by BAK1 and BKK1}

Yang Gao, Yujun Wu, Junbo Du, Yanyan Zhan, Doudou Sun, Jianxin Zhao, Shasha Zhang, Jia Li and Kai He*

Ministry of Education Key Laboratory of Cell Activities and Stress Adaptations, School of Life Sciences, Lanzhou University, Lanzhou, China

Receptor-like kinases BAK1 and BKK1 modulate multiple cellular processes including brassinosteroid signaling and PRR-mediated PTI in Arabidopsis. Our previous reports also demonstrated that bak1 bkk1 double mutants exhibit a spontaneous cell death phenotype under normal growth condition. With an unknown mechanism, the cell death in bak 1 bkk 1 is significantly suppressed when grown in dark but can be quickly induced by light. Furthermore, little is known about intrinsic components involved in BAK1 and $B K K 1$-regulated cell death pathway. In this study, we analyzed how light functions as an initiator of cell death and identified ETI components to act as mediators of cell death signaling in bak 1 bkk 1 . Cell death suppressed in bak 1 bkk 1 by growing in dark condition recurred upon exogenously treated SA. SA biosynthesis-related genes SID2 and EDS5, which encode chloroplast-localized proteins, were highly expressed in bak1-4 bkk1-1. When crossed to bak1-3 bkk1-1, sid2 or eds5 was capable of efficiently suppressing the cell death. It suggested that overly produced SA is crucial for inducing cell death in bak1 bkk1 grown in light. Notably, bak1-3 or bkk1-1 single mutant was shown to be more susceptible but bak1-3 bkk1-1 double mutant exhibited enhanced resistance to bacterial pathogen, suggesting immune signaling other than PTI is activated in bak 1 bkk 1 . Moreover, genetic analyses showed that mutation in EDS1 or PAD4, key ETI mediator, significantly suppressed the cell death in bak1-3 bkk1-1. In this study, we revealed that light-triggered SA accumulation plays major role in inducing the cell death in bak 1 bkk 1 , mediated by ETI components.

Keywords: Arabidopsis, BAK1, BKK1, cell death, light, SA, PTI, ETI

\section{INTRODUCTION}

Plant cells utilize plasma membrane (PM)-localized receptor-like kinases (RLKs) to communicate with each other and respond to environmental challenges in coordinating plant growth, development and stress adaptions. RLKs, the single-pass transmembrane proteins with an extracellular domain and a cytoplasmic kinase domain, play essential roles in transducing 
apoplastic signals into intracellular responses. Leucine-rich repeat (LRR)-RLK family is the largest RLK subfamily containing at least 223 members (Gou et al., 2010), a number of which were found to regulate a variety of physiological processes, such as phytohormone signaling ( $\mathrm{Li}$ and Chory, 1997; Li et al., 2002; Nam and Li, 2002), innate immunity (GómezGómez and Boller, 2000; Zipfel et al., 2006), meristem maintenance (Clark et al., 1997), pollen development (Zhao et al., 2002; Albrecht et al., 2005; Colcombet et al., 2005), stomatal development (Shpak et al., 2005), pollen tube-egg recognition (Escobar-Restrepo et al., 2007) and cell death control (He et al., 2007, 2008; Kemmerling et al., 2007) etc. Arabidopsis SOMATIC EMBRYOGENESIS RECEPTOR-LIKE KINASE (SERK) family, containing SERK1-SERK5, has become one of the best functionally analyzed LRR-RLK subfamilies (Li, 2010). SERK was originally isolated in carrot and identified as a marker gene of somatic embryogenesis (Schmidt et al., 1997). In Arabidopsis, SERKs were found to regulate various signaling pathways, in which they often play redundant roles. SERK1 and SERK2 regulate porogenesis by maintaining a normal tapetum during pollen maturation (Albrecht et al., 2005; Colcombet et al., 2005); SERK1, SERK3/BRI1-ASSOCIATED KINASE 1 (BAK1), and SERK4/BAK1-LIKE 1 (BKK1) act as co-receptors of the brassinosteroid (BR) receptor BRASSINOSTEROID INSENSITIVE 1 (BRI1) to perceive BRs and initiate cellular signaling cascade (Li et al., 2002; Nam and Li, 2002; Karlova et al., 2006; He et al., 2007; Gou et al., 2012).

BAK1 is also engaged in plant innate immunity. A twotiered system has been proposed to regulate plant innate immunity (Dodds and Rathjen, 2010). The first layer of immunity is activated after perceiving pathogen-associated molecular patterns (PAMPs) by pattern recognition receptors (PRRs) localized at the surface of a plant cell, known as PAMPtriggered immunity (PTI) (Macho and Zipfel, 2014). The second layer of immunity relies on recognition of pathogen-derived effectors by intracellular resistance (R) proteins in plants, known as effector-triggered immunity (ETI) (Jones and Dangl, 2006). PTI confers plant basal resistance to pathogens and ETI enables faster and stronger defense responses in plants, which is often accompanied with hypersensitive response (HR), a type of programmed cell death (PCD) (Jones and Dangl, 2006; Macho and Zipfel, 2014). Canonical R proteins are nucleotide-binding/leucine-rich repeat (NLR) receptors which fall into two groups, including CNLs, possessing a coiledcoil (CC) domain, and TNLs, containing a Toll-Interleukin1 receptor (TIR) domain (Meyers et al., 1999; Cannon et al., 2002). EDS1 and PAD4, two lipase-like proteins, are required for TNL-mediated ETI; while NDR1, a PM-associated protein, functions as key mediator in CNL signaling (Aarts et al., 1998; Wiermer et al., 2005; Knepper et al., 2011). BAK1 was found to be involved in PAMP recognition and mediating PTI via associating with several PRR RLKs such as FLAGELLINSENSITIVE 2 (FLS2), the receptor for bacterial flagellin, EF-TU RECEPTOR (EFR), the receptor for bacterial elongation factor $\mathrm{Tu}$ (EF-Tu), and PEP1 RECEPTOR 1 (PEPR1), the receptor for plant endogenous PROPEP-derived Pep epitopes (Chinchilla et al., 2007; Heese et al., 2007; Schulze et al., 2010). BAK1, therefore, positively regulates PTI, the first tier of plant innate immunity.

Intriguingly, our previous studies revealed $B A K 1 / S E R K 3$ and $B K K 1 / S E R K 4$ also mediate a cell death pathway that is independent of the BR signaling pathway (He et al., 2007). A null double mutant, bak1-4 bkk1-1, exhibits an extremely strong cell lesion phenotype even on the sterilized medium under normal growth condition. The cell death symptom of bak1-4 bkk11 emerged about 7 days after germination and eventually led to lethality within 2 weeks (He et al., 2007). The cell death phenotype we reported was in line with a simultaneous study of a different group showing that bak1-4 single mutant exhibited a runaway cell death upon microbial pathogen inoculation (Kemmerling et al., 2007).

Salicylic acid (SA) was identified as an essential signal molecule in mediating plant defense responses (Vlot et al., 2009). Serving as a crucial signal for activating disease resistance including PTI and ETI, SA is rapidly synthesized upon pathogen invasions. Arabidopsis mutants that fail to sufficiently synthesize endogenous SA exhibit impaired innate immunity and enhanced susceptibility to pathogen treatments (Rogers and Ausubel, 1997; Nawrath and Métraux, 1999; Wildermuth et al., 2001; Nawrath et al., 2002). Given that PR1 is a key marker gene of SA signaling, the extremely high expression of $P R 1$ suggested an exceedingly activated SA signaling in bak1-4 bkk1-1 (He et al., 2007). In Arabidopsis, SA is synthesized through two distinct routes, the phenylalanine ammonia-lyase (PAL) pathway and the isochorismate (IC) pathway (Dempsey et al., 2011). Chorismate, the end product of the shikimate pathway, is used as the SA precursor in both pathways (Dempsey et al., 2011). In Arabidopsis, four PAL proteins (PAL1-4) are essential for catalyzing the reaction from phenylalanine to trans-cinnamic acid, a critical step for SA production (Mauch-Mani and Slusarenko, 1996; Chen et al., 2009; Huang et al., 2010). The PAL pathway occurs in cytoplasm and was proposed to account for only 5\% of SA production (Métraux, 2002; Chen et al., 2009). The IC pathway, by contrast, takes place in chloroplast and contributes $95 \%$ of total cellular SA production (Wildermuth et al., 2001; Métraux, 2002; Garcion et al., 2008; Chen et al., 2009). Two redundant genes ISOCHORISMATE SYNTHASE 1 (ICS1) and ICS2 were identified to encode essential enzymes localized in chloroplasts to catalyze the conversion of chorismate to isochorismate, a key step of SA biosynthesis in the IC pathway (Garcion et al., 2008). Since ICS2 only plays a marginal role in this reaction, ICS1, also known as SALICYLIC ACID INDUCTION DEFICIENT 2 (SID2), functions as the determinate catalyzator of SA synthesis in IC pathway (Wildermuth et al., 2001; Garcion et al., 2008). Distinct from WT, ics1/sid2 single mutant plants showed no obvious SA accumulation upon a variety of stress treatments such as UV light, ozone, or pathogen incubations (Nawrath and Métraux, 1999; Garcion et al., 2008). The majority of SA, therefore, appears to be produced in chloroplasts and subsequently transported to cytosol and other cellular compartments to fulfill its physiological roles. It has been previously reported that ENHANCED DISEASE SUSCEPTIBILITY 5 (EDS5), a member of Multidrug and Toxic Compound Extrusion (MATE) transporter family, also impacts 
SA accumulation (Nawrath et al., 2002). EDS5 was suggested to be localized on plastid membrane and presumably function as an SA transporter in translocating SA from chloroplasts to cytosol (Serrano et al., 2013). Like ics1/sid2, eds5 mutants also failed to efficiently accumulate SA when exposed to pathogens (Nawrath and Métraux, 1999).

Little progress has been made since $B A K 1$ and $B K K 1$ were discovered to be essential in mediating a cell death pathway. One earlier study indicated that another LRR-RLK, BAK1-INTERACTING RECEPTOR-LIKE KINASE 1 (BIR1), can interact with BAK1, and that bir1 mutants displayed a cell death phenotype similar to that of the $b a k 1 b k k 1$ double mutants (Gao et al., 2009). A PM-localized copine-like protein, BONZAI1 (BON1), was identified as BAK1- and BIR1-interacting protein (Wang et al., 2011). The bon1 mutant plants also exhibited a cell-death phenotype (Yang et al., 2006). However, the detailed mechanisms of $B I R 1$ and $B O N 1$ in regulating cell death pathways and their connections to the $B A K 1$ and $B K K 1$-regulated cell death pathway remain elusive. Key open questions still await answers. For instance, what are the primary factors responsible for initiating cell death in bak1 bkk1 double mutant at early stage? Which biological processes are related to the cell death of bak1 bkk1? Our previous report suggested that light likely serves as a key factor in triggering cell death in bak1-4 bkk11 (He et al., 2008). Distinct from the bak1-4 bkk1-1 plants starting to exhibit lesion symptom at 7 days when grown under a long-day condition, bak1-4 bkk1-1 grown in darkness did not display a cell death phenotype at 8 days (He et al., 2008). The mechanism regarding how light contributes to triggering cell death in bak1 bkk1 has not been depicted. Despite the well establishment of BAK1 as an essential co-receptor of key PRRs in positively regulating PTI, the cell death occurring in bakl bkk1 seems to be unrelated to PTI. Overexpression or knocking-out of known BAK1-associated PRRs does not cause cell death in plants. Instead, the cell death phenotype of bak1-4 bkk1-1 resembles HR, a typical defense response in ETI. It implies $B A K 1$ and $B K K 1$ play roles beyond PTI. However, whether ETI regulatory components are involved in the cell death pathway mediated by $B A K 1$ and $B K K 1$ remains unknown.

In this study, we carefully analyzed the light-triggered cell death in bak1 bkk1 mutants. Our results indicated that SA accumulation in bak1 bkk1 mutants may function as a primary initiator to trigger cell death. Genes encoding chloroplastlocalized proteins SID2 and EDS5 that are essential for SA biosynthesis and accumulation were highly up-regulated in bak1 bkk1 and played critical roles in cell death formation. Further analyses revealed that, despite maintaining their insensitivity to bacterial PAMP, bakl bkk1 mutants exhibited overly activated immunity, suggesting $B A K 1$ and $B K K 1$ mediate a different immunity signaling besides PTI. At last, our results showed that the loss-of-function mutation of PAD4 or EDS1, key component mediating ETI, was capable of significantly suppressing the cell death of a weak double mutant, bak1-3 $b k k 1-1$. These results provide genetic evidence suggesting the involvement of ETI in BAK1 and BKK1-mediated cell death pathway.

\section{MATERIALS AND METHODS}

\section{Plant Materials and Growth Conditions}

All of the Arabidopsis lines used in this study are in the Col-0 ecotype except pif1-1 (Col-3). T-DNA insertion lines bak1-4 (SALK_116202), bak1-3 (SALK_034523), $b k k 1$-1 (SALK_057955), sid2-3 (SALK_088254), eds52 (SALK_091541C), pad4-2 (SALK_089936), eds1-3 (SALK_057149), pif1-1 (CS66041), pif3-1 (SALK_030753), pif4-3 (SALK_140393C), pif5-3 (SALK_087012C) were obtained from the Arabidopsis Biological Resource Center (ABRC). Multiple mutants were generated by genetic crossings. Homozygous plants were isolated via PCR with genotyping primers designed by http://signal.salk.edu/tdnaprimers.2.html. The wildtype and mutant plants were grown in greenhouse or illumination incubator at $22^{\circ} \mathrm{C}$ in dark condition or under long day cycle (16 $\mathrm{h}$ light/8 h dark). For SA treatment assay, seedlings were grown on $0.5 \times$ Murashige and Skoog medium with or without SA in dark condition and were analyzed at indicated days.

\section{Trypan Blue Staining and DAB Staining}

Tissue stainings with trypan blue and DAB were carried out as previously described (He et al., 2007).

\section{Determination of Subcellular Distribution}

The full length CDS of SID2 and EDS5 were amplified by RT-PCR and cloned into pBIB-BASTA-35S-GWR-GFP and pBIB-BASTA-35S-GWR-YFP, respectively. The two constructs were transformed into Agrobacterium tumefaciens strain GV3101. The transformed GV3101 were cultured in LB medium (supplemented $20 \mu \mathrm{M}$ acetosyringone) about 12-16 h. Centrifuged and re-suspended the cultured cells with injection buffer (liquid MS medium containing $150 \mu \mathrm{M}$ acetosyringone, $10 \mathrm{mM} \mathrm{MgCl}_{2}, 10 \mathrm{mM}$ MES, pH 5.7) and adjusted to $\mathrm{OD}_{600}=$ 0.5 . After quiescence for $2 \mathrm{~h}$, the cultures were injected into the $N$. benthamiana mesophyll tissue. $N$. benthamiana protoplasts were isolated after 3 days of injection. YFP or GFP fluorescence signal was observed by Olympus FluoView FV1000 confocal microscope.

\section{Gene Expression Analyses}

For quantitative RT-PCR (qRT-PCR) assays, total RNA was extracted from the whole seedlings harvested under different time points. Two micrograms of total RNA was reversely transcribed in a $20 \mu \mathrm{l}$ volume with M-MLV reverse transcriptase (Invitrogen). The fragments of target genes were amplified using SYBR Premix Ex Taq (TaKaRa). The thermal cycling program was $95^{\circ} \mathrm{C}$ for $30 \mathrm{~s}$, followed by 40 cycles of $95^{\circ} \mathrm{C}$ for $5 \mathrm{~s}, 60^{\circ} \mathrm{C}$ for 30 s. ACTIN2 (At3G18780) was used for normalization the relative expression level of each transcript, and the comparative $\Delta \Delta \mathrm{C}_{\mathrm{T}}$ method was employed to calculate the relative quantities of each amplified product. For identification of mutant alleles, total RNA was isolated from the leaves of 11-day-old plants grown in soil. Two micrograms of total RNA was reversely transcribed in a $20 \mu \mathrm{l}$ volume using M-MLV reverse transcriptase (Invitrogen). The transcripts of specific genes were amplified with gene-specific primers. ACTIN2 was used as a reference. The 
primers used for qRT-PCR and semi-quantitative RT-PCR are listed in Table S1.

\section{Measurements of SA Content}

SA content measurements were carried out as previously described (Du et al., 2016).

\section{Bacterial Infection Assays}

Pst DC3000-LUX strain expressing luxCDABE operon was cultured in $\mathrm{KB}$ medium for $12 \mathrm{~h}$. Centrifuged and re-suspended the cultured cells with $10 \mathrm{mM} \mathrm{MgCl}_{2}$ and adjusted to $\mathrm{OD}_{600}$ $=0.2$. The Pst DC3000-LUX suspension was sprayed onto the 3-week-old Arabidopsis plant lines indicated. All the sprayed plants were kept under a transparent lid to keep high humidity conditions. The plants were checked by a CCD camera to obtain the images of luciferase fluorescence at $30 \mathrm{~h}$ after inoculation. The experiments were repeated three times.

\section{flg22 Treatments}

Diluted flg22 with sterilized $0.5 \times$ Murashige and Skoog solution (pH5.7) to the concentration of $0.2 \mu \mathrm{M}$. Nine-day-old Col-0, bak1-4 bkk1-1, bak1-4 and bkk1-1 grown on $0.5 \times$ Murashige and Skoog medium were immersed with flg22 solution for 5 , 15 , and $30 \mathrm{~min}$. Total protein was extracted from the seedlings harvested under different time points. The total protein extracts were separated by a 10\% SDS-PAGE gel for western blot assay. P-p44/42 (Cell Signaling Technology) was used as the antibody. Equal loadings were tested by staining the SDS-PAGE gel with Coomassie brilliant blue G250.The experiments were repeated three times.

\section{RESULTS}

\section{Initiation of the Cell Death in bak1-4 bkk1-1 Was Light-Dependent}

In order to elucidate the mechanism of light-induced cell death in bak1 bkk1, we analyzed bak1-4 bkk1-1 mutant plants under a variety of light conditions. Consistent with our earlier results, dark-grown bak1-4 bkk1-1 showed no clear cell death symptom 8 days after germination, similar to WT Col-0 plants (Figure 1A). Next, Col-0 and bak1-4 bkk1-1 plants were first grown in dark for 4 days then transferred to a long-day condition (16 h light/8 h dark). bak1-4 bkk1-1 started to exhibit cell death 2 days after transferring to light (Figure 1A). By contrast, no cell death was detected in dark-grown Col-0 subsequently treated by light (Figure 1A). These results indicated that dark condition prevented bak1-4 bkk1-1 from forming cell death, which was quickly triggered by light. Cell death is often accompanied with ROS burst, which could be either the cause or consequence of cell death (Chaouch and Noctor, 2010). DAB staining was used to visualize the accumulation of $\mathrm{H}_{2} \mathrm{O}_{2}$. Col-0 did not accumulate $\mathrm{H}_{2} \mathrm{O}_{2}$ under either light or dark condition (Figure 1B). ROS burst was only detected in dark-grown bak1-4 bkk1-1 after exposure to light (Figure 1B), displaying patterns similar to cell death formation (Figure 1A). Under light condition, the initiation of cell death was found to be 1 day prior to overaccumulation of ROS in bak1-4bkk1-1. These results suggested that, instead of causing cell death, ROS burst may be the physiological consequence of cell death in bak1-4 bkk1-1.

Next, we examined whether the defense response of bak1$4 b k k 1-1$ was also related to light. Utilizing qRT-PCR, a SAresponsive gene, $P R 1$, and a cell death marker gene, FOM1 (Bartsch et al., 2006; Li et al., 2013), were checked. Col-0 and bak1-4 bkk1-1 grown in dark for 4 days then transferred to long-day condition for 1 or 2 days were analyzed. After being transferred to a long-day condition for 1 or 2 days, PR1 in dark-grown bak1-4 bkk1-1 increased about 17 or 600-fold, respectively, compared to the one in Col-0 (Figure 2A). In Col$0, P R 1$ gene was kept at constantly low expression levels under both dark and light conditions (Figure 2A). FMO1 expression was also significantly induced when dark-grown bak1-4 bkk11 was exposed to light for 1 or 2 days (Figure 2B), consistent with trypan blue straining results (Figure 1A). As control PR1 and FOM1 genes were also analyzed in the seedlings grown in continuous dark. In contrast to the significantly increased expression of PR1 and FMO1 in dark-grown bak1-4 bkk1-1 after light treatment, when grown in dark for 5 or 6 days, the expression of PR1 and FMO1 showed slight increases or almost no changes in bak1-4 bkk1-1 compared to the ones in Col0 (Figures 2A,B). Since PR1, a marker gene of SA signaling pathway, was highly expressed in bak1-4 bkk1-1 upon light exposure, it was conjectured SA may contribute to the lightinduced cell death mediated by $B A K 1$ and $B K K 1$. The SA contents were measured in Col-0, bak1-4, bkk1-1, and bak1-4 bkk1-1 seedlings grown in dark for 4 days and the seedling grown in dark for 4 days followed by exposure to long-day condition for 1 day. The free SA in Col-0 and single mutant plants grown in dark for 4 days was unchanged after transferring to a long-day condition for 1 day. In bak1-4 bkk1-1 grown under dark for 4 days, free SA increased about 3-fold after growing the plants in long-day condition for 1 day, indicating a quick SA accumulation in bak1-4 bkk1-1 upon light treatment (Figure 2C). Similarly, total SA in bak1-4 bkk1-1 plants was also significantly increased when moved from dark to light condition (Figure 2D). Notably, high concentration of total SA was already detected in bak1-4 $b k k 1-1$ plants grown in dark before light treatment (Figure 2D). This result suggested that $B A K 1$ and $B K K 1$ may also regulate a pathway inactivating SA.

The majority of SA is synthesized in chloroplasts where SID2/ICS1 serves as a determinate enzyme (Wildermuth et al., 2001; Métraux, 2002; Garcion et al., 2008; Chen et al., 2009). A minor portion of SA is produced in cytoplasm, which is catalyzed by PALs (Métraux, 2002; Chen et al., 2009). To explicate why total SA was accumulated in bak1-4 bkk1-1 even under a dark condition, we analyzed the expression levels of PAL1-4 genes. In dark, the expression of all four $P A L$ genes increased in bak1$4 b k k 1-1$ compared to those in Col-0 (Figure S1). The elevated expression of $P A L$ genes in $b a k 1-4 b k k 1-1$ may contribute to the accumulation of total SA in a dark condition, when free SA was still kept at low concentrations.

Interestingly, cell death eventually started to be detectable in bak1-4 bkk1-1 at 12 days when grown in dark (Figure S2). These results indicated that the cell death phenotype was extensively 


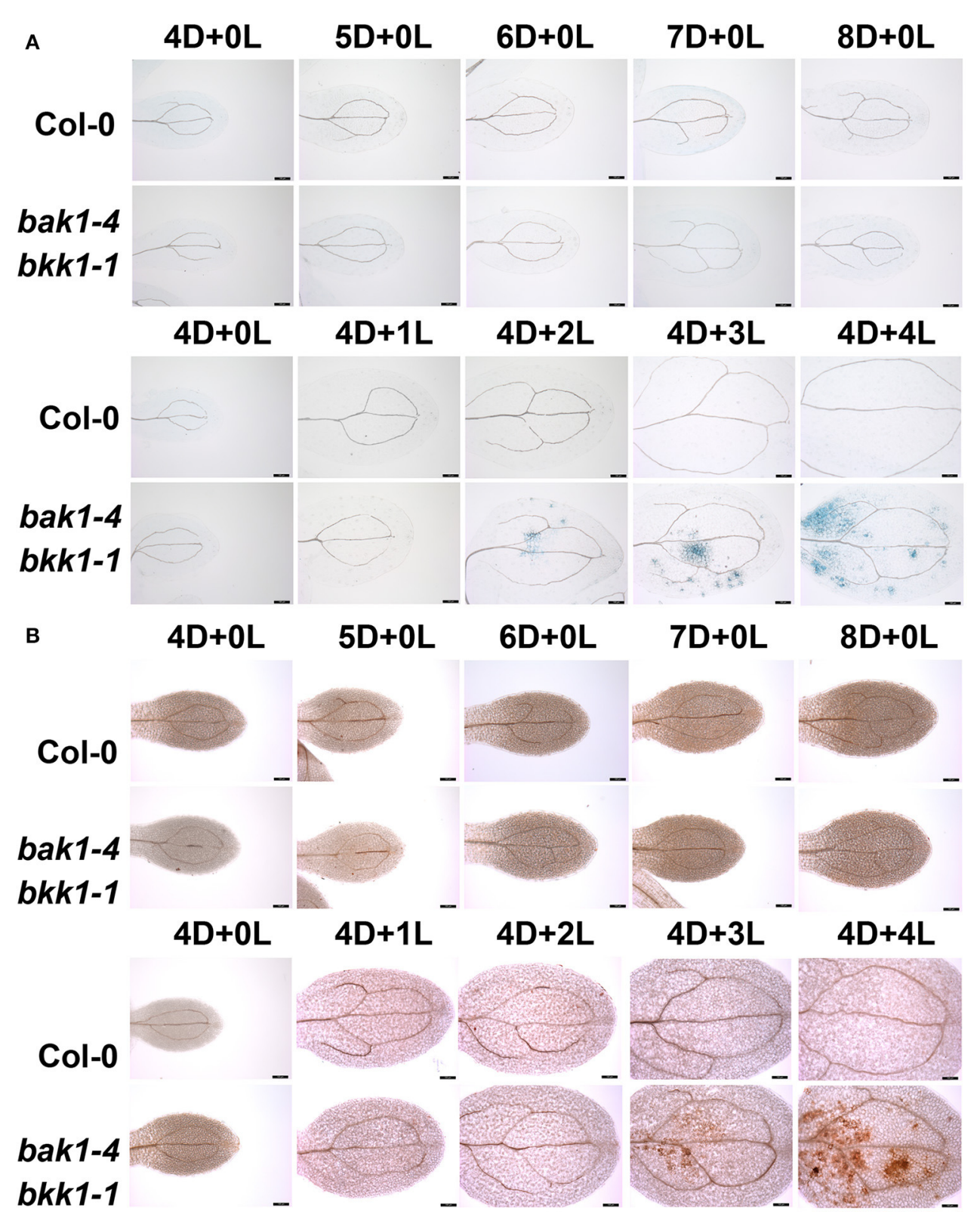

FIGURE 1 | Light initiates cell death in bak1-4 bkk1-1. Seedlings are grown in dark (D) for 4 days then relocated to long-day condition (L) for the indicated days $(4 \mathrm{D}+1 \mathrm{~L}, 4 \mathrm{D}+2 \mathrm{~L}, 4 \mathrm{D}+3 \mathrm{~L}, 4 \mathrm{D}+4 \mathrm{~L})$. Seedlings grown in dark (D) for the indicated days $(4 \mathrm{D}+\mathrm{OL}, 5 \mathrm{D}+\mathrm{OL}, 6 \mathrm{D}+\mathrm{OL}, 7 \mathrm{D}+\mathrm{OL}, 8 \mathrm{D}+\mathrm{OL})$ are presented as control. The trypan blue staining assays indicate cell death symptom is induced in bak1-4 bkk1-1 2 days after the transfer from dark to light condition (A). The DAB staining assays indicate ROS accumulation is detected in bak1-4 bkk1-1 3 days after the transfer from dark to light condition (B). The scale bars represent $100 \mu \mathrm{m}$.

delayed but not completely abolished in bak1-4 bkk1-1 when grown in dark.

\section{Exogenously Applied SA Triggered Cell Death in bak1-4 bkk1-1 in Dark}

Given that the initiation of light-dependent cell death in bak1$4 b k k 1-1$ was likely SA-related, we further analyzed the detailed role of SA in cell death induction. Trypan blue staining was used to detect cell death in Col-0 and bak1-4 bkk1-1 grown on $1 / 2 \mathrm{MS}$ medium supplemented with 0,10 , or $50 \mu \mathrm{M}$ SA in dark condition. Col-0 showed no cell death when treated with 10 or $50 \mu \mathrm{M}$ SA (Figure 3A). When grown on the medium supplemented with $50 \mu \mathrm{M}$ SA in a dark condition, bak1-4 bkk11 started to show cell death symptom 5 days after germination. When treated with $10 \mu \mathrm{M}$ SA in dark, bak1-4 bkk1-1 also exhibited obvious but less severe cell death symptom compared to those treated with $50 \mu \mathrm{M}$ SA (Figure 3A). These results clearly demonstrated that cell death suppressed in bak1-4 bkk11 by growing the seedlings in dark condition reappeared by exogenously treated SA. Therefore, SA seemed to reproduce the 
A

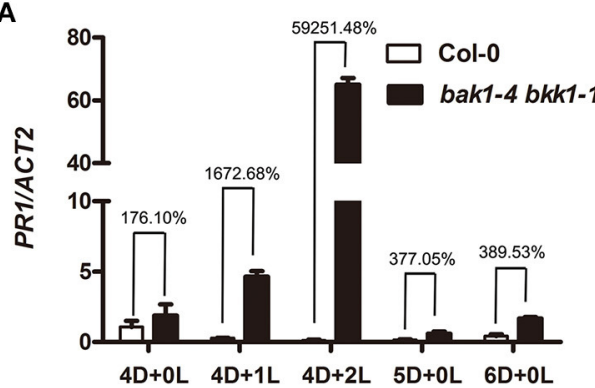

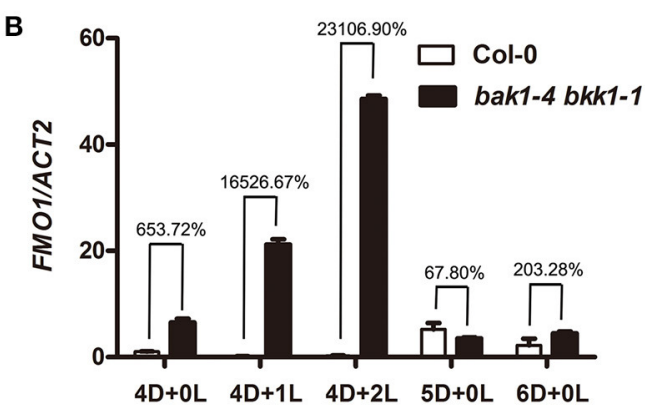

4D+0L 4D+1L 4D+2L 5D+0L 6D+0L

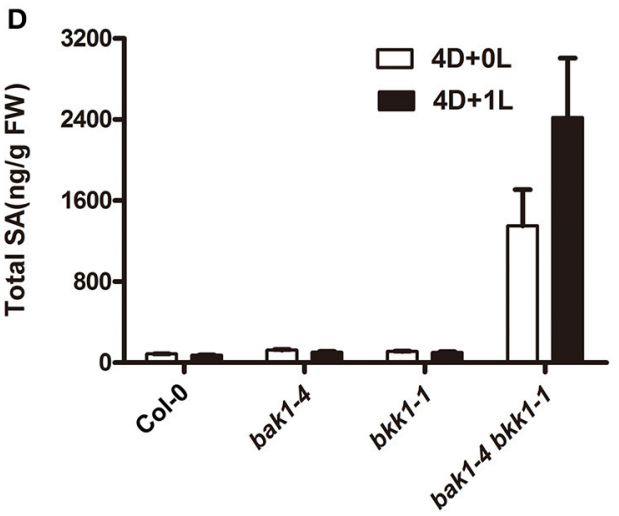

FIGURE 2 | The transcripts of PR1 and FMO1 and SA content in bak1-4 bkk1-1 are significantly elevated upon light treatment. Quantitative RT-PCR assays demonstrate the expression of SA marker gene PR1 (A) and cell death marker gene FMO1 (B) is extensively up-regulated in bak1-4 bkk1-1 by light. Free SA (C) and total SA (D) contents increase in bak1-4 bkk1-1 1 day after the transfer from dark to long-day condition. Seedlings grown in dark (D) for 4 days then relocated to long-day condition ( $L$ ) for the indicated days (4D+1L, 4D+2L) and seedlings grown in dark (D) for the indicated days (4D+OL, 5D+OL, 6D+OL) are analyzed.

effect of light with regard to cell death induction in bak1-4 bkk1-1. ROS accumulation was also examined in Col-0 and bak1-4 bkk11 plants upon SA treatment. This result suggested that $\mathrm{H}_{2} \mathrm{O}_{2}$ was also accumulated in bak1-4 bkk1-1 but not in Col-0 when SA was applied to the medium (Figure 3B). In dark condition, the ROS burst in bak1-4 bkk1-1 appeared 1 day after the emergence of cell death symptom when treated with SA (Figure 3), similar to the patterns of light-induced cell death and ROS burst in bak1-4 bkk1-1 (Figure 1).

\section{The Expression of SID2 and EDS5 Was Highly Elevated in bak1 bkk1}

SA-induced cell death in bak1-4 bkk1-1 was light-independent, supporting light plays an indirect role in the induction of cell death in bak1-4 bkk1-1. SA accumulation may contribute to this process. We first analyzed whether light signaling pathways were involved in $B A K 1$ and $B K K 1$-mediated cell death. A weak double mutant bak1-3 bkk1-1 was crossed to several pif mutants to generate triple and quadruple mutant lines. PIF genes encode transcription factors mediating red light and blue light signaling pathways. PIF1 usually functions redundantly with PIF3, and PIF4 often plays an overlapping role with PIF5. Our genetic results demonstrated that none of bak1-3 bkk1-1 pif1-1, bak1-3 bkk1-1 pif3-1, or bak1-3 bkk1-1 pif1-1 pif3-1 mutant plants displayed a phenotypic difference in cell death symptom compared to their background bak1-3 bkk1-1
(Figure S3). Similarly, bak1-3 bkk1-1 pif4-3, bak1-3 bkk1-1 pif53, or bak1-3 bkk1-1 pif4-3 pif5-3 mutant plants did not show alterations to bak1-3 bkk1-1 with regard to cell death phenotype (Figure S4). These results suggested that the PIF-mediated light signalings may not contribute to the cell death initiation in bak1 $b k k 1$ under light condition. Thus, it was hypothesized that SA synthesis, mainly occurring in chloroplast and relying on lightdependent photomorphogenesis, plays a key role in the lightinduced cell death in bakl bkk1. Through data mining of our earlier microarray results that compare global gene expression patterns between Col-0 and bak1-4 bkk1-1 seedlings, we noticed that two genes, SID2 and EDS5, encoding critical components involved in SA biosynthesis and cytoplasmic accumulation, were dramatically up-regulated in $b a k 1-4 b k k 1-1$. The microarray data indicated that the transcripts of SID2 and EDS5 in bak1-4 bkk11 increased 19.86 and 5.78-fold, respectively, compared to the ones in Col-0. Interestingly enough, the protein products of these two genes were both suggested to locate to chloroplast. SID2 encodes an isochorismate synthase catalyzing chorismate into isochorismate, a SA precursor, in chloroplast. EDS5 encodes a MATE transporter, locating to the chloroplast envelope, and is suggested to function as an SA transporter mediating the translocation of chloroplast-synthesized SA to cytosol. Using a quantitative RT-PCR assay, we analyzed the expression patterns of SID2 and EDS5 in Col-0 and bak1-4 bkk1-1 plants grown in dark condition for 4 days and the plants grown in dark for 


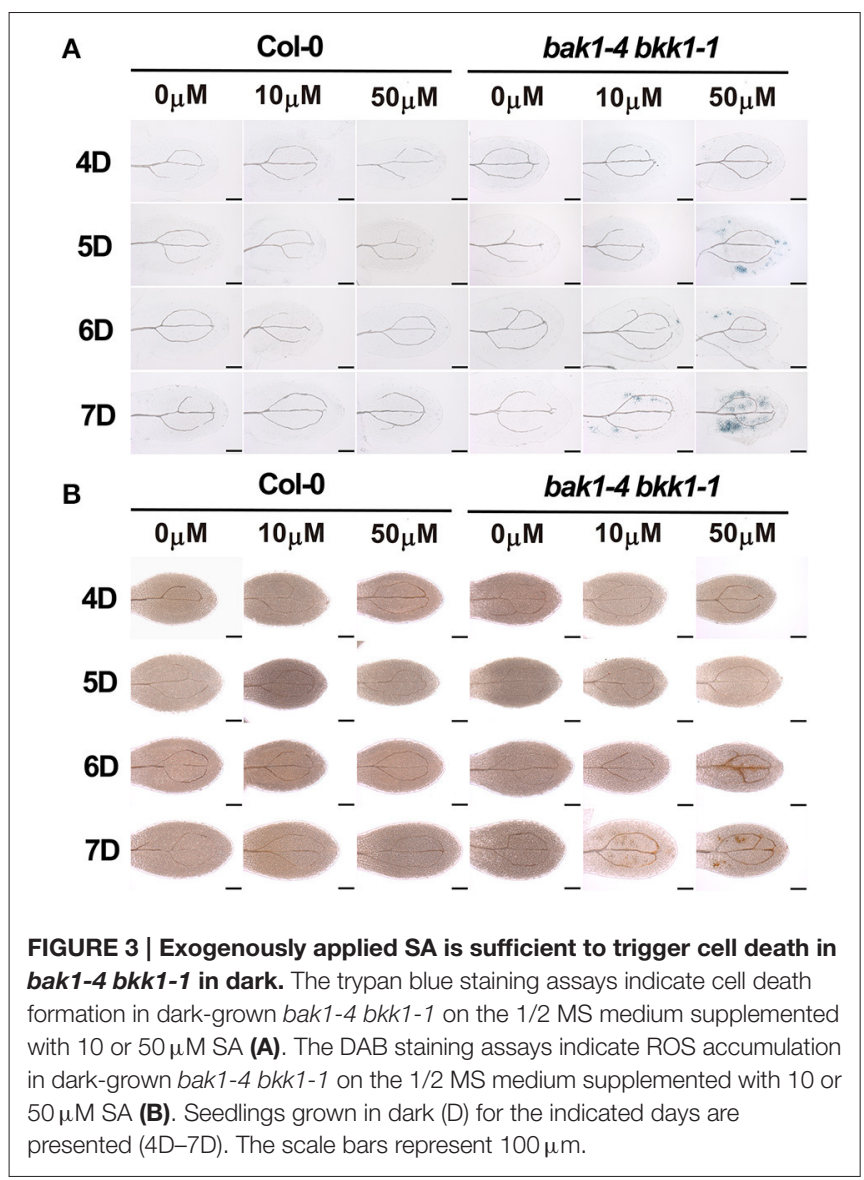

4 days then exposed in long-day condition for 1 or 2 days. SID2 showed significantly high expression in bak1-4 bkk1-1 (Figure 4A), indicating a robustly negative regulation on SID2 expression by $B A K 1$ and $B K K 1$. Treated with or without light condition, the transcripts of SID2 increased about 30-40-fold in bak1-4 bkk1-1 compared to those in Col-0 (Figure 4A), suggesting the inhibition on SID2 expression by BAK1 and $B K K 1$ was likely light-independent. In dark, the expression of EDS5 increased about 2-fold in bak1-4 bkk1-1 compared to the one in Col-0 (Figure 4A). Upon Light treatment, EDS5 expression decreased in Col-0 but increased in bak1-4 bkk11 (Figure 4A), suggesting EDS5 is also suppressed by BAK1 and $B K K 1$, especially under light condition. When grown in dark for 5 or 6 days, SID2 and EDS5 in bak1-4 bkk1-1 showed much lower levels of increases (Figure 4A). We next analyzed the subcellular locations of SID2 and EDS5 proteins. The cDNAs of SID2 and EDS5 were fused with GFP and $Y F P$, respectively, and transiently expressed in N. benthamiana, driven by $35 S$ promoter. SID2-GFP was detected to be localized in chloroplast (Figure 4B). EDS5-YFP mainly located to the surface of chloroplast (Figure 4B), consistent with the previous report that EDS5 may function as an SA transporter at the chloroplast envelope. Taken together, our results indicated SID2 and EDS5, encoding chloroplast-localized proteins essential for SA accumulation, were suppressed by $B A K 1$ and $B K K 1$ at transcriptional levels.

\section{Mutation of SID2 or EDS5 Partially Suppressed the Cell Death in bak1-3 bkk1-1}

In order to further dissect the function of SID2 and EDS5 in initiating cell death in $b a k 1 b k k 1$, genetic approaches were employed. bak1-3 bkk1-1 was crossed to sid2-3 and eds5-2 TDNA insertion lines, respectively, to generate triple-mutants. RTPCR results confirmed that SID2 and EDS5 were completely knocked out in bak1-3 bkk1-1 sid2-3 and bak1-3 bkk1-1 eds52 , respectively (Figure S5). Introduction of sid2-3 into bak1-3 bkk1-1 significantly suppressed the cell death symptom of bak1-3 $b k k 1-1$ when grown in soil for 3-week-old (Figure 5A). Trypan blue and DAB staining results confirmed SID2 mutation greatly inhibited the cell death phenotype and ROS accumulation in 11-day-old bak1-3 bkk1-1 (Figures 5B-E,H-K). In addition, the highly expressed PR1 and FMO1 in bak1-3 bkk1-1 restored to WT-like levels in bak1-3 bkk1-1 sid2-3 triple mutant, indicating SID2 is essential for cell death induction in bak1-3 bkk1-1 (Figures 5N,O). Similarly, the absence of EDS5 also appeared to partially rescue the cell death phenotype of 3-week-old bak13 bkk1-1 (Figure 5A). Trypan blue and DAB staining results verified that the cell death and ROS burst in 11-day-old bak1-3 $b k k 1-1$ eds5-2 was largely prevented (Figures 5B-M). The qRTPCR results showed that the expression of $P R 1$ and FMO1 was greatly suppressed in bak1-3 bkk1-1 eds5-2 compared to the ones in bak1-3 bkk1-1 (Figures 5N,O). Collectively, our genetic results indicated SA biosynthesis-related genes SID2 and EDS5 act as crucial components in promoting cell death in bakl-3 bkk1-1.

\section{bak1 bkk1 Showed Enhanced Bacterial Resistance and Impaired PTI}

Since it is established that BAK1 positively regulates PTI via interacting and collaborating with several PRRs, we further examined the basal defense in bak1 bkk1. Three-week-old soil-grown plants of Col-0, sid2-3, eds5-2, bak1-3, bkk1-1, bak1-3 bkk1-1, bak1-3 bkk1-1 sid2-3, and bak1-3 bkk1-1 eds5-2 were sprayed with P. syringae pv tomato DC3000 (Pst DC3000)-LUX for $30 \mathrm{~h}$ before the images of luciferase florescence were taken. Single mutant sid2-3 or eds5-2 showed enhanced susceptibility to the bacterial pathogen, indicating the essential role of SA in mediating basal defense (Figure 6A). Similarly, single mutant bak1-3 or bkk1-1 also exhibited markedly reduced resistance to Pst DC3000, consistent with the notion that $B A K 1$ functions as a positive regulator in PTI (Figure 6A). Surprisingly, the double mutant bak1-3 bkk1-1 showed enhanced resistance to Pst DC3000, different from either bak1-3 or bkk1-1 (Figure 6A). Compared to bak1-3 bkk1-1, bak1-3 bkk1-1 sid2-3 or bak1-3 bkk1-1 eds5-2 showed reduced bacterial resistance, suggesting SA was involved in the defense activation in bak1-3 bkk1-1. To confirm these results, we analyzed the activation status of MPK3/6 in various plants lines. MPK $3 / 6$ were identified as mediators in basal defense and receptor triggered immunity including PTI and ETI (Rasmussen et al., 2012; Tsuda et al., 2013). Activated MPK3/6 via phosphorylation indicate enhanced immune response. By using 

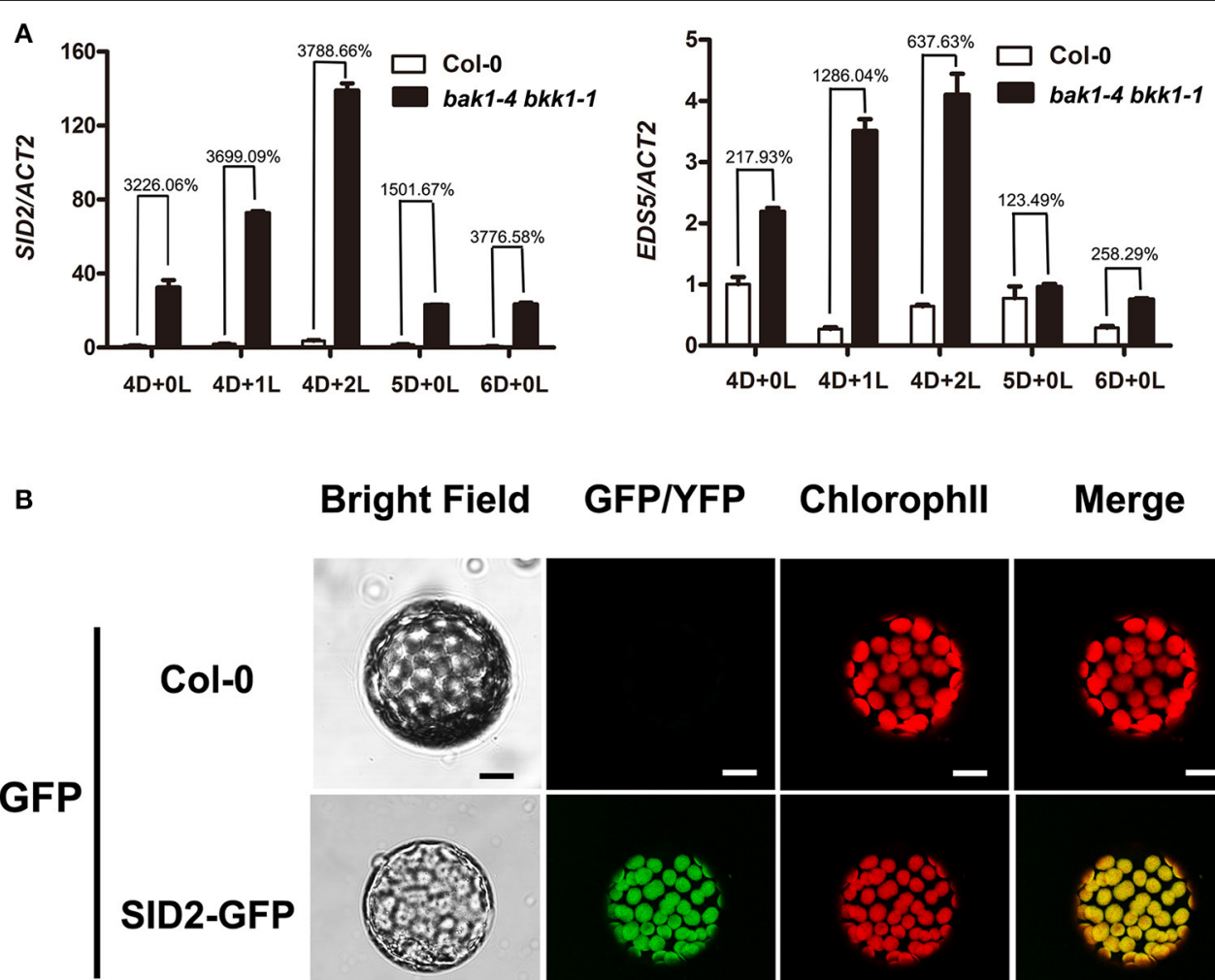

Bright Field

GFP/YFP Chlorophll

Merge
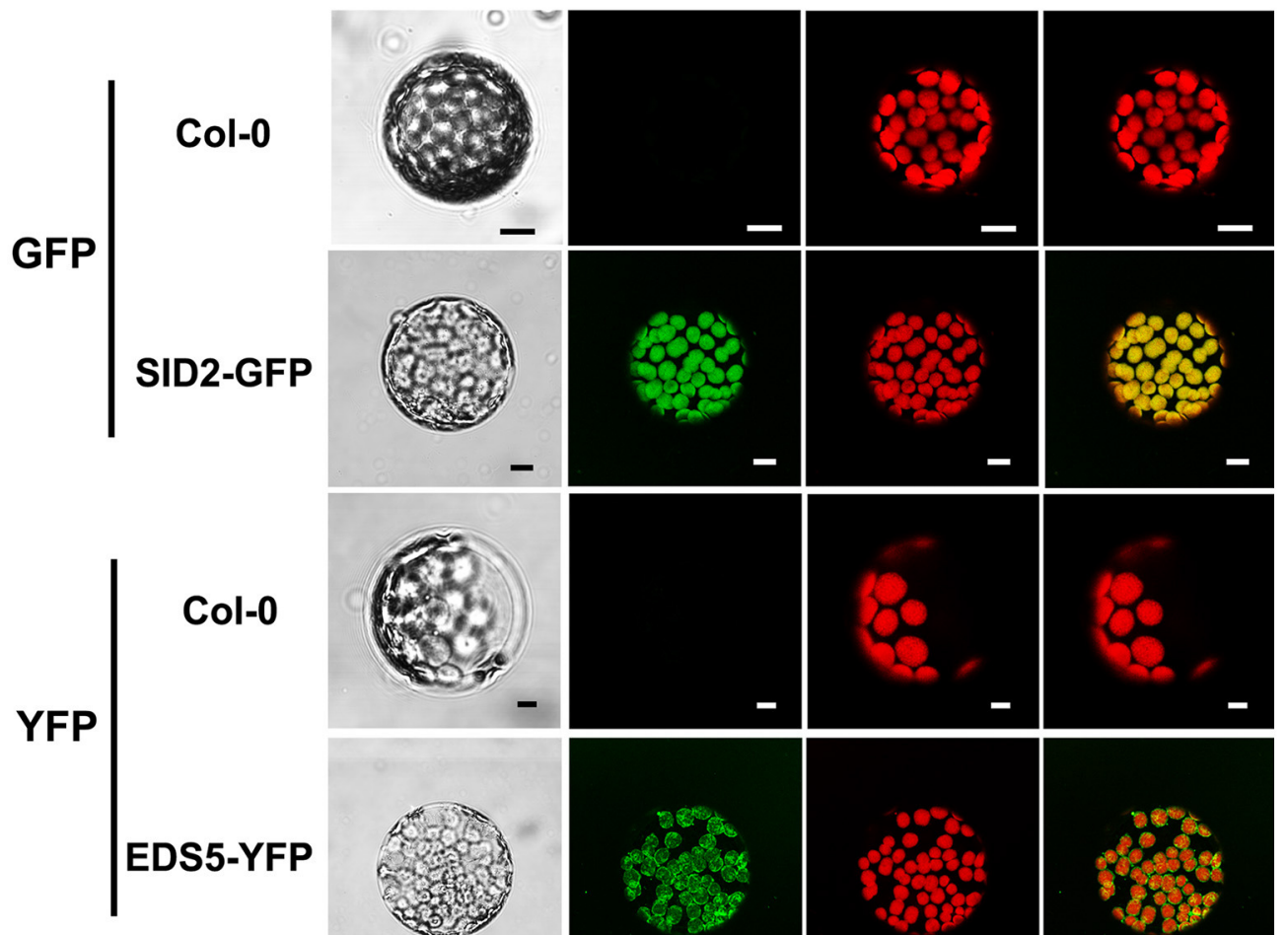

$-$
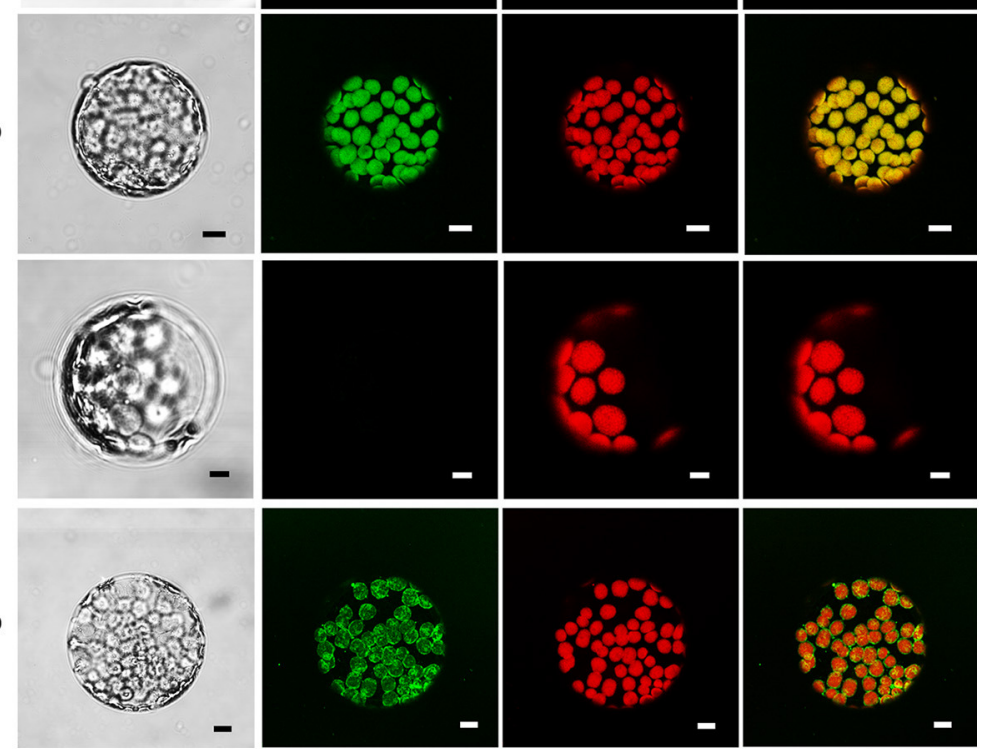

FIGURE 4 | BAK1 and BKK1 robustly suppress the expression of SA biosynthesis-related genes SID2 and EDS5. Seedlings are grown in dark (D) for 4 days then relocated to long-day condition $(\mathrm{L})$ for the indicated days (4D+OL, 4D+1L, 4D+2L). Seedlings grown in dark for 5 or 6 days (5D+OL or $6 \mathrm{D}+0 \mathrm{~L})$ are analyzed as control. Quantitative RT-PCR assays indicate both SID2 and EDS5 are significantly up-regulated in bak1-4 bkk1-1 compared to those in Col-0 (A). SID2-GFP and EDS5-YFP are detected to locate to the entire chloroplast and chloroplast surface, respectively, in $N$. benthamiana protoplasts (B). The scale bars represent $10 \mu \mathrm{m}$.

a P-p44/42 antibody, phosphorylated MPK3/6 were detected in various plant lines. Consistent to Pst DC3000 treatment results, bak1-3 bkk1-1 showed over-activated MPK3/6, which were less phosphorylated in sid2-3, eds5-2, bak1-3, bak1-4, or $b k k 1-1$, compared to Col-0 (Figure 6B). In bak1-3 bkk1-1 sid2-3 and bak1-3 bkk1-1 eds5-2, phosphorylated MPK3/6 were reduced compared to bak1-3 bkk1-1, suggesting the autoimmunity in bak1-3 bkk1-1 is partially SA-dependent (Figure 6B). It was intriguing that $b a k 1-3$ and $b k k 1-1$ single mutants were more susceptible but bak1-3 bkk1-1 double mutant were more resistant to bacterial pathogen. We next analyzed PTI signaling in bak1 bkk1 to examine whether PTI was responsible for the enhanced immunity in bak1-4 bkk1-1. Nine-day-old Col-0, bak1-4bkk1-1, bak1-4, and bkk1-1 were incubated with flg22, a 22-amino-acid peptide conserved in bacterial flagellin that is efficient to trigger FLS2-mediated immune signaling, for 5,15 , and $30 \mathrm{~min}$ before examining phosphorylated MPK3/6. Both of the single mutants bak1-4 and $b k k 1-1$ showed reduced response to flg22 (Figure 6C). The response of double mutant bak1-4 bkk1-1 to flg22 was dramatically reduced, demonstrating PTI in bak1-4 bkk1-1 was nearly blocked (Figure 6C). Our results supported the 

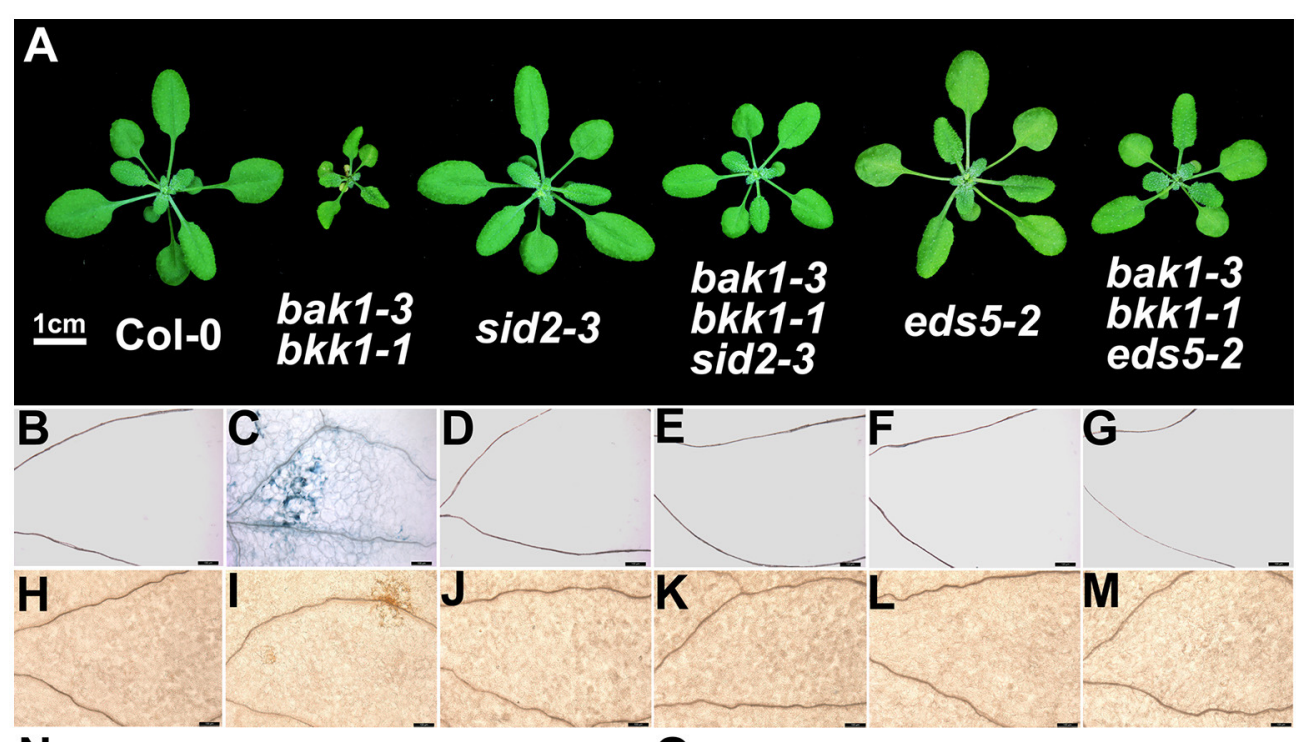

$\mathbf{N}$
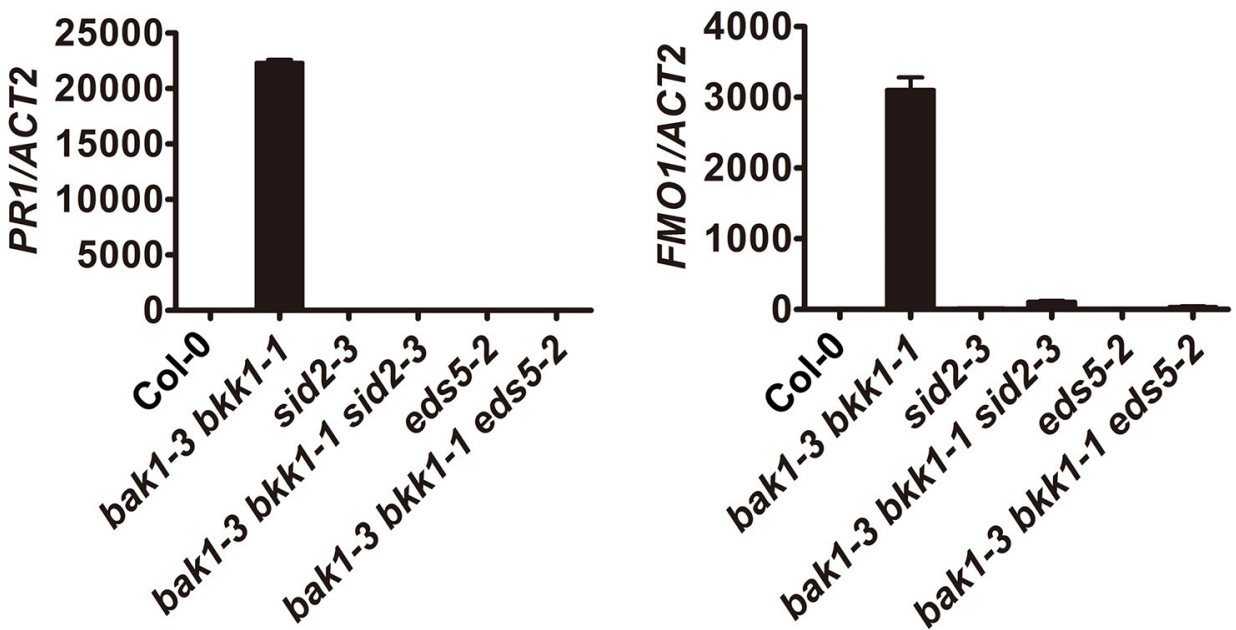

FIGURE 5 | The cell death in bak1-3 bkk1-1 is significantly suppressed by the mutation in SID2 or EDS5. The representative phenotypes of 3-week-old Col-0, bak1-3 bkk1-1, sid2-3, bak1-3 bkk1-1 sid2-3, eds5-2, and bak1-3 bkk1-1 eds5-2 grown in soil are presented (A).Trypan blue staining (B-G) and DAB staining (H-M) assays indicate the cell death and ROS accumulation in bak1-3 bkk1-1 are largely prevented in bak1-3 bkk1-1 sid2-3 and bak1-3 bkk1-1 eds5-2. Quantitative RT-PCR assays indicate the highly expressed PR1 and FMO1 in bak1-3 bkk1-1 are restored to WT-like levels in bak1-3 bkk1-1 sid2-3 and bak1-3 bkk1-1 eds5-2

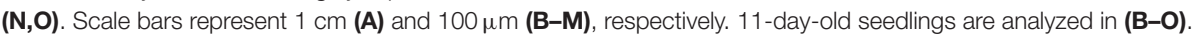

previous findings that $B A K 1$ is essential for PRR-mediated PTI and, more importantly, suggested that bak1 bkk1 double mutants undergo an enhanced immune signaling other than PTI.

\section{EDS1 and PAD4, Components Mediating ETI, Were Involved in the Cell Death in bak1 bkk1}

EDS1-PAD4 complex acts as an essential component in mediating all tested TNL type $\mathrm{R}$ protein pathway in ETI (Wiermer et al., 2005). To understand whether ETI is involved in the cell death induction in bak1 bkk1, bak13 bkk1-1 was crossed to eds1-3 and pad4-2, respectively eds1-3 was able to partially rescue the cell death of bak13 bkk1-1; while pad4-2 dramatically suppressed the lesion symptom of bak1-3 bkk1-1 (Figure 7A). Our genetic results thus implicated the autoimmunity in bak1 bkk1 is likely ETIrelated.

Given that EDS1 and PAD4 also function as upstream of SA pathway via regulating ICS1-generated SA biogenesis, we next tested whether the suppression of bak1-3 bkk1-1 by eds 1 or pad4 was SA-dependent. No clear cell death symptom was detected in 3-week-old bak1-3 bkk1-1 sid2-3 (Figure 5). By contrast, 26-day-old bak1-3 bkk1-1 sid2-3 started to exhibit detectable 

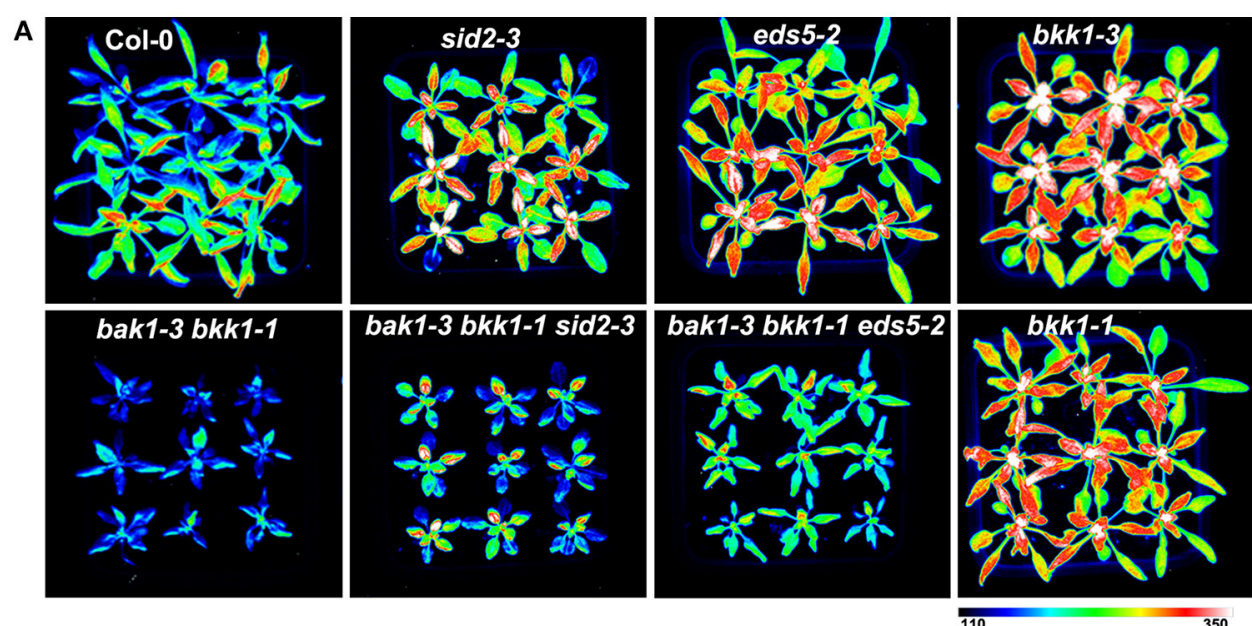

B
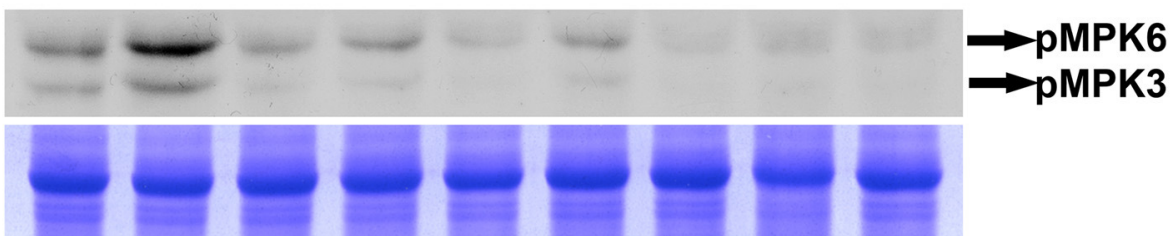

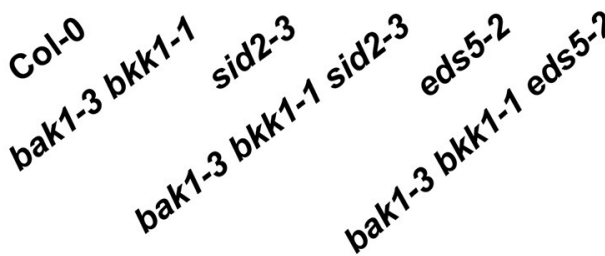

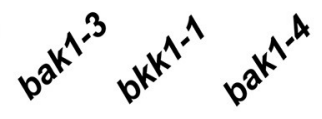

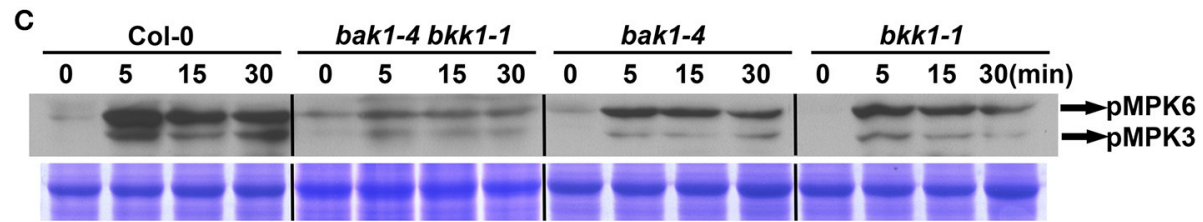

FIGURE 6 | bak1-3 bkk1-1 shows enhanced resistance to bacterial pathogen. The image of 3-week-old Col-0, bak1-3 bkk1-1, sid2-3, bak1-3 bkk1-1 sid2-3, eds5-2, bak1-3 bkk1-1 eds5-2, bak1-3, and bkk1-1 grown in soil is presented at $30 \mathrm{~h}$ after sprayed with Pst DC3000-LUX (A). The western blot assay shows the phosphorylation levels of MPK3/MPK6 in 2-week-old Col-0, bak1-3 bkk1-1, sid2-3, bak1-3 bkk1-1 sid2-3, eds5-2, bak1-3 bkk1-1 eds5-2, bak1-3, bak1-4, and bkk1-1 (B). The western blot assay shows the phosphorylation levels of MPK3/MPK6 in 9-day-old Col-0, bak1-4 bkk1-1, bak1-4, and bkk1-1 treated with flg22 (C). Seedlings are grown in soil (B) and $0.5 \times$ Murashige and Skoog medium (C), respectively.

lesion symptom, suggesting the cell death pathway was partially SA-dependent. The cell death of bak1-3 bkk1-1 sid2-3 was further suppressed by eds1 or pad4, suggesting EDS1 and PAD4 contributed to the BAK1 and BKK1-mediated cell death pathway other than, or in addition to, regulating SA accumulation (Figure 7B). Therefore, ETI mediated by EDS1 and PAD4 was proposed to be involved in BAK1-mediated cell death pathway. We also introduced a mutation of NDR1, a key mediator in CNL signaling, into bak1-3 bkk1-1. The triple mutant bak1-3 $b k k 1-1$ ndr1-1 exhibited identical cell death phenotype to bak13 bkk1-1, suggesting TNL type but not CNL type R proteins are likely involved in BAK1 and BKK1-mediated cell death pathway (Figure S6).

\section{DISCUSSION}

BAK1 was originally identified as a co-receptor of BRI1, positively regulating $B R$ signal transduction. Genetic analyses revealed that $B A K 1$ and its closest homolog $B K K 1$ can also modulate a cell death pathway that is independent of the BR signaling pathway. This unexpected finding suggested the versatile roles of BAK1 in regulating plant growth and development, as well as adaptations to environmental stresses. Removal of both $B A K 1$ and $B K K 1$ in a single plant leads to cell lesion and ultimately a lethality phenotype under a normal growth condition, indicating the irreplaceable roles $B A K 1$ and $B K K 1$ play in the physiological events essential for plants to fulfill their life cycles. However, 

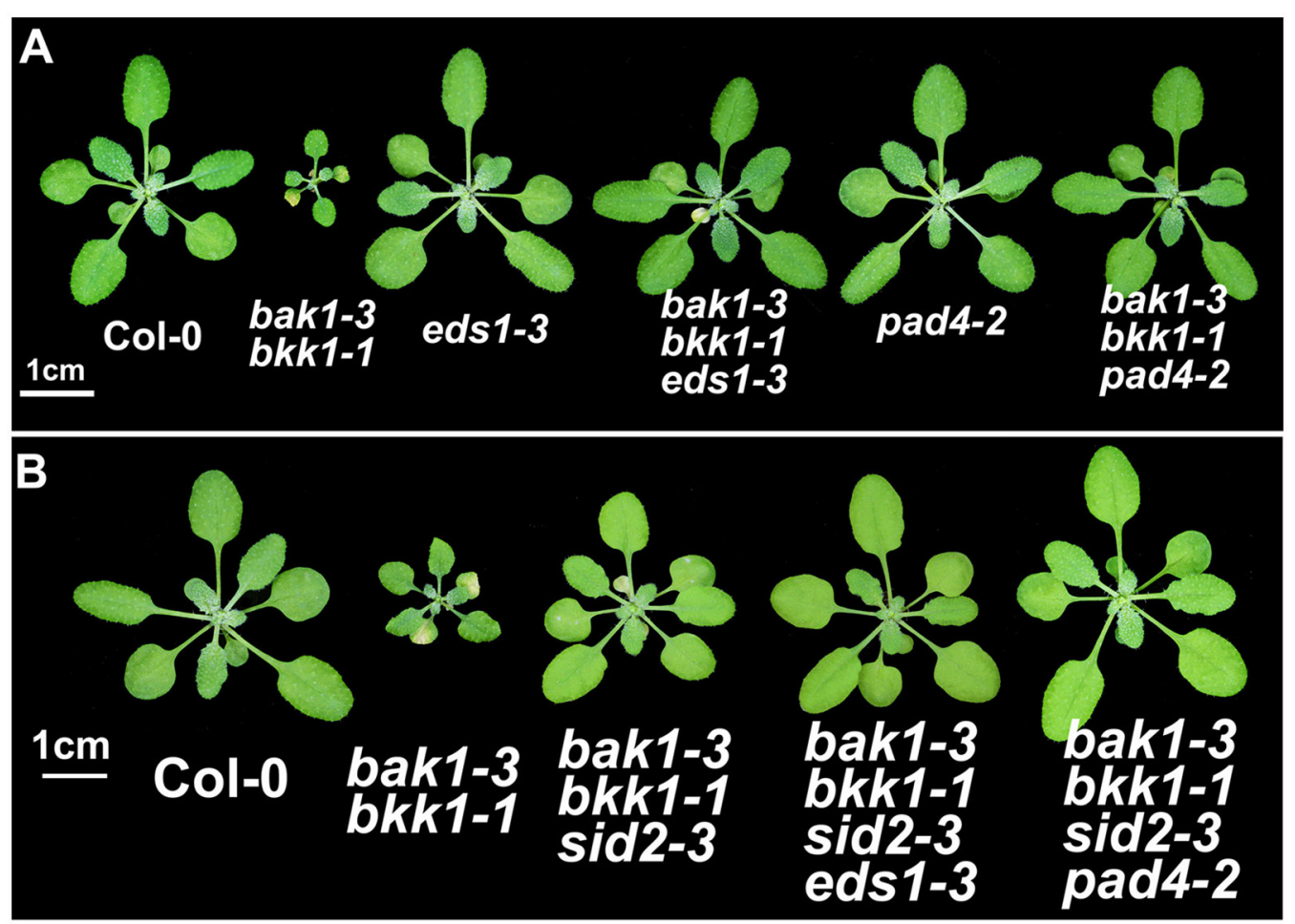

C

\section{BAK1/BKK1}

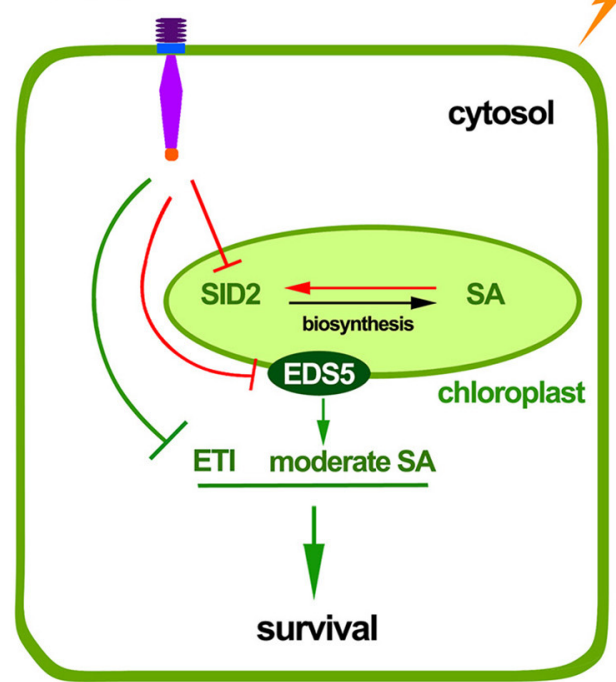

BAK1/BKK1 depletion

light

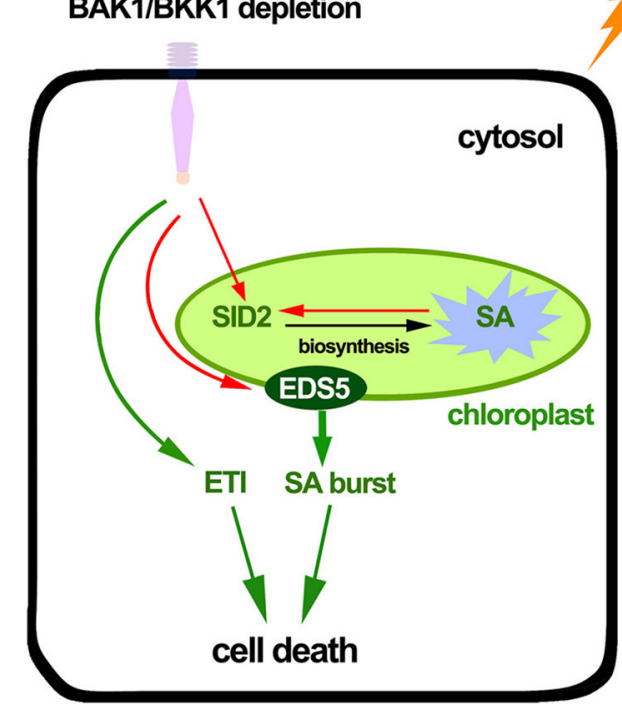

transcriptional level

FIGURE 7 | The cell death in bak1-3 bkk1-1 is significantly suppressed by the mutation in EDS1 or PAD4. The representative phenotypes of 3-week-old Col-0, bak1-3 bkk1-1, eds1-3, bak1-3 bkk1-1 eds1-3, pad4-2 and bak1-3 bkk1-1 pad4-2 grown in soil are presented (A). The representative phenotypes of 26-day-old Col-0, bak1-3 bkk1-1, bak1-3 bkk1-1 sid2-3, bak1-3 bkk1-1 sid2-3 eds1-3, and bak1-3 bkk1-1 sid2-3 pad4-2 grown in soil are presented (B). A hypothetical model for the cell death induction in bak1 bkk1. Under light condition, BAK1 and BKK1 repress SID2 and EDS5 at transcriptional levels, resulting in low concentrations of cellular SA. The absence of both BAK1 and BKK1 leads to highly expressed SID2 and EDS5, causing overly produced endogenous SA in the chloroplast followed by SA transport to cytosol through EDS5. Positive feedback regulation of SID2 by SA causes SA burst that ultimately triggers cell death. BAK1 and BKK1 also suppress ETI signaling mediated by EDS1-PAD4. Depletion of both BAK1 and BKK1 leads to release of the inhibition on ETI. Activated ETI induces cell death (HR) and confers plants enhanced resistance (C). 
the detailed mechanisms of $B A K 1$ and $B K K 1$ in mediating cell death are still beyond what we understand. After the finding of $B A K 1$-mediated cell death, BAK1 was reported to be engaged in plant innate immunity through associating with PRRs such as FLS2, EFR and PEPR1 (Chinchilla et al., 2007; Heese et al., 2007; Schulze et al., 2010). Nevertheless, loss-of-function mutants of the BAK1-interacting PRRs only exhibit impaired innate immunity but no cell death symptom, suggesting the cell death mediated by BAK1 and BKK1 is unlikely directly related to PTI mediated by PRRs. In addition, a BAK1 point mutation allele, bak1-5, was identified to display disrupted FLS2-mediated PTI, but bak1-5 bkk1-1 showed no cell death (Schwessinger et al., 2011), suggesting that BAK1-mediated PTI pathway and BAK1mediated cell death pathway belong to distinct signaling events.

Our previous research suggested dark growth condition largely suppressed the cell death symptom in bak1-4 bkk1-1 and light treatment quickly induced lesion phenotype in dark-grown bak1-4 bkk1-1. How light serves as an initiator of cell death in bak1 bkk1 mutants is still unclear. Furthermore, the downstream signaling components involved in cell death induction in bak1 $b k k 1$ are nearly unknown. Considering that PTI is not likely involved in the cell death of bak1 bkk1, ETI, the stronger immune response featured by quick cell death formation, is worth being investigated whether is related to $B A K 1$ and $B K K 1$-mediated cell death pathway.

In this study, we analyzed the formation of cell death in bak1 bkk1 upon light treatment. Our results indicated that cell death was undetectable in bak1-4 bkk1-1 when grown in dark up to 12 days, while evident lesion symptom was induced in bak1-4 bkk1-1 2 days after being transferred from dark to light condition, accompanied with highly accumulated SA and ROS. Fascinatingly, dark-grown bak1-4 bkk1-1 was capable of exhibiting obvious cell death when exogenous SA was applied, illustrating that light does not directly regulate cell death and SA might function downstream of light and play a central role in promoting the cell death in bak1 bkk1. qRT-PCR results revealed that two genes SID2 and EDS5, critical in modulating SA biosynthesis, were significantly up-regulated in bak1-4 bkk11 ; and more interestingly, the protein products of both genes are located in chloroplasts. The mutation in either SID2 or EDS5 in bak1-3 bkk1-1 remarkably rescued the cell death phenotype of the double mutant, suggesting chloroplast-localized SID2 and EDS5 are crucial for cell death formation in bak1-3 bkk1-1, likely via affecting SA accumulation. Furthermore, in a pathogen treatment assay, both bakl-3 and bkk1-1 single mutants were more susceptible to Pst DC3000 compared to Col-0, consistent to the notion that BAK1 functions as major contributor to the basal resistance to several pathogens including Pst DC3000 (Roux et al., 2011). Surprisingly, bak1-3 bkk1-1 double mutant exhibited enhanced resistance to Pst DC3000, indicating the loss of either $B A K 1$ or $B K K 1$ causes impaired immunity but removing both $B A K 1$ and $B K K 1$ leads to triggering additional route of plant immunity instead. Genetic analyses supported this notion by showing that mutation in either EDS1 or PAD4, key regulator mediating ETI, resulted in suppression of cell death in bakl bkk1.

Based on the aforementioned results, we propose a hypothetic model. SA is not efficiently synthesized in bakl bkk1 in dark condition. Light-induced overexpression of SID2 and EDS5 in bak1 bkk1 causes highly accumulated SA. Positive feedback regulation on SA biosynthetic genes by high concentrations of SA further enhances the SA biosynthesis and leads to SA burst that ultimately induce cell death in bak1 bkk1. In addition, BAK1 and BKK1 regulate a signaling pathway to inhibit ETI, which is mediated by EDS1-PAD4 complex, under normal growth conditions. When BAK1 and BKK1 are both depleted, ETI is activated to initiate cell death in plants, a faster and stronger defense response (Figure 7C).

Light has been reported to cause cell death when it is excessive (Szechyńska-Hebda and Karpiński, 2013); and UV light treatment often leads to lesions in plant tissues (Nawkar et al., 2013). Nevertheless, the light-dependent cell death found in bak1 bkk1 seems to be distinct from the known lightinduced cell death. The known light-induced lesion is caused by rapid ROS accumulation, a key cell death signal. In bak1 $b k k 1$ double mutants, the cell death symptom appears prior to the accumulation of ROS, indicating ROS is not the cause of the cell death. Instead, ROS accumulation is likely an effect of cell death in bak1 bkk1. Nevertheless, since ROS also serves as a feedback signal for SA biosynthesis (Torres et al., 2006), the ROS accumulation in bak1 bkk1 may further deteriorate the cell death symptom. In addition, none of the multiple bakl-3 bkk1-1 pif mutant plants displayed altered lesion phenotype compared with bak1-3 bkk1-1 (Figures S3, S4), suggesting light-induced cell death in bakl bkk1 is independent of PIF-mediated blue and red light signaling pathways (Castillon et al., 2007; Pedmale et al., 2016). Moreover, the effect of light on cell death initiation can be reproduced by SA treatment in bakl bkk1 in dark (Figure 3), suggesting light acts as an indirect factor to trigger cell death in bakl bkk1 and light signaling is not essential for this process.

Compared to those in Col-0, the transcripts of SID2 increased about 30-40-fold in bak1-4 bkk1-1, demonstrating SID2 expression is strongly inhibited by $B A K 1$ and $B K K 1$. Even though the expression of SID2 was indeed enhanced by light, the suppression of SID2 by BAK1 and BKK1 seemed to be lightindependent, indicated by similar multiple increases of SID2 in dark-grown Col-0 and bak1-4 bkk1-1 upon light treatment (Figure 4A). The expression of EDS5 is suppressed by BAK1 and $B K K 1$. Compared to those in Col-0, EDS5 transcripts increased about 2 -fold in dark condition, but elevated around 12-fold 1 day after relocating to light condition in bak1-4 bkk1-1. This result suggested the expression of EDS5 is synergistically controlled by light and BAK1and BKK1 (Figure 4).

In PAL pathway of SA synthesis, four PAL genes were identified to encode enzymes facilitating production of the SA precursor in cytosol. Our results suggested the expression levels of $P A L$ genes were also inhibited by $B A K 1$ and $B K K 1$. It may explicate that high total SA content was detected under dark condition in bak1-4 bkk1-1. The PAL-dependent SA biosynthesis pathway may contribute to the cell death initiation in bak1-4 bkk1-1 when grown in dark for an elongated period of time (Figures S1, S2). It is also possible that additional BAK1 and BKK1-mediated pathway that is SA-independent may contributes to the cell death signaling. Despite high concentration of total SA in bak1-4 bkk1-1 in dark, the free SA 
content was almost equal to that in Col-0. Thus, $B A K 1$ and $B K K 1$ might control an unknown SA regulation pathway conjugating SA to other components, serving as a mechanism of preventing toxicity caused by highly accumulated free SA (Dempsey et al., 2011).

A recent study indicated that bak1 mutant exhibited enhanced resistance to Pst DC3000, through reprogramming PEPRmediated defense signaling. Upon Pst DC3000 treatment, PROPEP genes were up-regulated at $24 \mathrm{hpi}$ (hours postinoculation) and bak1 was more resistant at 3 dpi (days postinoculation) (Yamada et al., 2016). It suggested the resistance to Pst DC3000 found in bak1 is caused by activation of an additional immune response, the PEPR-mediated signaling. To wipe out the potential interference by secondary response in bak1, we examined the early responses of various plant lines to Pst DC3000 at $30 \mathrm{hpi}$. Instead, the single mutant bak1-3 or bkk1-1 was more susceptible to Pst DC3000, which is in line with previous studies showing that BAK1 serves as a co-receptor for multiple PRRs and the mutation of BAK1 causes impaired PTI and reduced resistance (Chinchilla et al., 2007; Heese et al., 2007; Schulze et al., 2010; Roux et al., 2011; Schwessinger et al., 2011). It is interesting that bak1-3 bkk1-1 double mutant was more resistant to Pst DC3000 (Figure 6A). In an flg22 treatment assay, we confirmed that the sensitivity of flagellin PAMP was almost abolished in bak1-4 bkk1-1 (Figure 6C). Thus, bak1 bkk1 double mutant maintains a dampened PTI but exhibits enhanced pathogen resistance. Therefore, additional immune signaling must be activated in bak1-3 bkk1-1. Our results showed that eds1 or pad4 can significantly suppress the cell death phenotype of bak1-3 bkk1-1, supporting the notion that ETI is inhibited by BAK1 and BKK1-mediated signaling (Figure 7A). It explained why bak1-3 $b k k 1-1$ was more resistant to pathogen. Although EDS1-PAD4 complex was known to regulate SA via affecting ICS1-generated SA biosynthesis, the suppression of bak1-3 bkk1-1 by eds1 or pad4 appears to be SA-independent. bak1-3 bkk1-1 sid2-3 showed lesion phenotype when grown for an extended period of time. eds1 or pad4 suppressed the cell death of bak1-3 bkk1-1 sid2-3, suggesting EDS1-PAD4 regulate BAK1-mediated cell death signaling via a SA-independent manner (Figure $7 \mathbf{B}$ ). In a recent report, it was shown that the major function of EDS1 and PAD4 in mediating ETI is SA-independent (Rietz et al., 2011). This study was in line with our results showing that sid 2 only partially suppressed the cell death of bak1-3 bkk1-1 and that eds1 or pad4 further enhanced the suppression of cell death in bak1-3 bkk1-1 sid2-3.

Pathogen-derived effectors target key components mediating PTI in plant cell. FLS2, EFR, or CERK1 (CHITIN ELICITOR RECEPTOR KINASE 1) was shown to be the substrate of several

\section{REFERENCES}

Aarts, N., Metz, M., Holub, E., Staskawicz, B. J., Daniels, M. J., and Parker, J. E. (1998). Different requirements for EDS1 and NDR1 by disease resistance genes define at least two R gene-mediated signalling pathways in Arabidopsis. Proc. Natl. Acad. Sci. U.S.A. 95, 10306-10311. doi: 10.1073/pnas.95.17.10306 effectors such as Pto, a kinase inhibitor, PtoB, a ubiquitin ligase, and HopAO1, a tyrosine phosphatase (Göhre et al., 2008; Xiang et al., 2008; Gimenez-Ibanez et al., 2009; Macho et al., 2014). The association between PRRs and effectors leads to dysfunction or degradation of PRRs, a strategy of pathogens to suppress plant immunity and enhance pathogenesis. BAK1, the co-receptor of several key PRRs, is also the target of several effectors, including PtoB, HopF2, an ADP-ribosyltransferase, and HopB1, a protease (Shan et al., 2008; Zhou et al., 2014; Li et al., 2016). It seems to be an efficient way for invading pathogens to attack a co-receptor in order to interrupt multiple PRR-mediated immune signalings. In our model, BAK1 and BKK1 may serve as guard proteins to surveil pathogen invasions. Depletion of BAK1 and BKK1 caused by effector attacks activates ETI, the stronger immunity featured by induction of cell death (HR), to enhance plant resistance to pathogens (Figure 7C).

In this study, we investigated the mechanism of how light functions as a primary factor in initiating cell death in bak1 $b k k 1$. Our results supported light-induced overly expressed SA biosynthetic genes play a central role in this process. We also found key ETI components contribute to the cell death formation in $b a k 1 b k k 1$. Future studies will focus on whether R proteins, the initiators of ETI signaling, function as downstream substrates of BAK1 and BKK1 and are engaged in the cell death induction in bak1 bkk1.

\section{AUTHOR CONTRIBUTIONS}

$\mathrm{KH}$, JL, and YG designed the experiments. YG, YW, JD, YZ, DS, $\mathrm{JZ}$, and SZ performed the experiments. $\mathrm{KH}$ and $\mathrm{YG}$ analyzed the data and wrote the manuscript.

\section{ACKNOWLEDGMENTS}

We thank Dr. Guojing Li for providing technical support for SA measurements, and the Arabidopsis Biological Resource Center for other seed stocks. These studies were supported by the grant from the National Natural Science Foundation of China to $\mathrm{KH}$ (31471305), the Ministry of Agriculture of the People's Republic of China (2016ZX08009-003-002), the Fundamental Research Funds for the Central Universities to KH (lzujbky-2016-75), and the grant from the National Natural Science Foundation of China to JL (31530005 and 31470380).

\section{SUPPLEMENTARY MATERIAL}

The Supplementary Material for this article can be found online at: http://journal.frontiersin.org/article/10.3389/fpls.2017. 00622/full\#supplementary-material 
signaling in Arabidopsis immunity and cell death is regulated by the monooxygenase FMO1 and the nudix hydrolase NUDT7. Plant Cell 18, 1038-1051. doi: 10.1105/tpc.105.039982

Cannon, S. B., Zhu, H., Baumgarten, A. M., Spangler, R., May, G., Cook, D. R., et al. (2002). Diversity, distribution, and ancient taxonomic relationships within the TIR and non-TIR NBS-LRR resistance gene subfamilies. J. Mol. Evol. 54, 548-562 doi: 10.1007/s0023901-0057-2

Castillon, A., Shen, H., and Huq, E. (2007). Phytochrome interacting factors: central players in phytochrome-mediated light signalling networks. Trends Plant Sci. 12, 514-521. doi: 10.1016/j.tplants.2007.10.001

Chaouch, S., and Noctor, G. (2010). Myo-inositol abolishes salicylic acid-dependent cell death and pathogen defence responses triggered by peroxisomal hydrogen peroxide. New Phytol. 188, 711-718. doi: $10.1111 / j .1469-8137.2010 .03453 . x$

Chen, Z., Zheng, Z., Huang, J., Lai, Z., and Fan, B. (2009). Biosynthesis of salicylic acid in plants. Plant Signal. Behav. 4, 493-496. doi: 10.4161/psb.4.6.8392

Chinchilla, D., Zipfel, C., Robatzek, S., Kemmerling, B., Nurnberger, T., Jones, J. D. G., et al. (2007). A flagellin-induced complex of the receptor FLS2 and BAK1 initiates plant defence. Nature 448, 497-500. doi: 10.1038/nature05999

Clark, S. E., Williams, R. W., and Meyerowitz, E. M. (1997). The CLAVATA1 gene encodes a putative receptor kinase that controls shoot and floral meristem size in Arabidopsis. Cell 89, 575-585. doi: 10.1016/S0092-8674(00)80239-1

Colcombet, J., Boisson-Dernier, A., Ros-Palau, R., Vera, C. E., and Schroeder, J. I. (2005). Arabidopsis SOMATIC EMBRYOGENESIS RECEPTOR KINASES1 and 2 are essential for tapetum development and microspore maturation. Plant Cell 17, 3350-3361. doi: 10.1105/tpc.105.036731

Dempsey, D. A., Vlot, A. C., Wildermuth, M. C., and Klessig, D. F. (2011). Salicylic acid biosynthesis and metabolism. Arabidopsis Book 9:e0156. doi: 10.1199/tab.0156

Dodds, P. N., and Rathjen, J. P. (2010). Plant immunity: towards an integrated view of plant-pathogen interactions. Nat. Rev. Genet.11, 539-548. doi: $10.1038 / \mathrm{nrg} 2812$

Du, J., Gao, Y., Zhan, Y., Zhang, S., Wu, Y., Xiao, Y., et al. (2016). Nucleocytoplasmic trafficking is essential for BAK1 and BKK1-mediated celldeath control. Plant J. 85, 520-531. doi: 10.1111/tpj.13125

Escobar-Restrepo, J.-M., Huck, N., Kessler, S., Gagliardini, V., Gheyselinck, J., Yang, W.-C., et al. (2007). The FERONIA receptor-like kinase mediates male-female interactions during pollen tube reception. Science 317, 656-660. doi: 10.1126/science.1143562

Gao, M., Wang, X., Wang, D., Xu, F., Ding, X., Zhang, Z., et al. (2009). Regulation of cell death and innate immunity by two receptor-like kinases in Arabidopsis. Cell Host Microbe 6, 34-44. doi: 10.1016/j.chom.2009.05.019

Garcion, C., Lohmann, A., Lamodière, E., Catinot, J., Buchala, A., Doermann, P., et al. (2008). Characterization and biological function of the ISOCHORISMATE SYNTHASE2 gene of Arabidopsis. Plant Physiol. 147, 1279-1287. doi: $10.1104 /$ pp.108.119420

Gimenez-Ibanez, S., Hann, D. R., Ntoukakis, V., Petutschnig, E., Lipka, V., and Rathjen, J. P. (2009). AvrPtoB targets the LysM receptor kinase CERK1 to promote bacterial virulence on plants. Curr. Biol. 19, 423-429. doi: 10.1016/j.cub.2009.01.054

Göhre, V., Spallek, T., Häweker, H., Mersmann, S., Mentzel, T., Boller, T., et al. (2008). Plant pattern-recognition receptor FLS2 is directed for degradation by the bacterial ubiquitin ligase AvrPtoB. Curr. Biol. 18, 1824-1832. doi: $10.1016 /$ j.cub.2008.10.063

Gómez-Gómez, L., and Boller, T. (2000). FLS2: an LRR receptor-like kinase involved in the perception of the bacterial elicitor flagellin in Arabidopsis. Mol. Cell 5, 1003-1011. doi: 10.1016/S1097-2765(00)80265-8

Gou, X., He, K., Yang, H., Yuan, T., Lin, H., Clouse, S. D., et al. (2010). Genome-wide cloning and sequence analysis of leucine-rich repeat receptorlike protein kinase genes in Arabidopsis thaliana. BMC Genomics 11:19. doi: 10.1186/1471-2164-11-19

Gou, X., Yin, H., He, K., Du, J., Yi, J., Xu, S., et al. (2012). Genetic evidence for an indispensable role of somatic embryogenesis receptor kinases in brassinosteroid signalling. PLoS Genet. 8:e1002452. doi: 10.1371/journal.pgen.1002452

He, K., Gou, X., Powell, R. A., Yang, H., Yuan, T., Guo, Z., et al. (2008). Receptorlike protein kinases, BAK1 and BKK1, regulate a light-dependent cell-death control pathway. Plant Signal. Behav. 3, 813-815. doi: 10.4161/psb.3.10.5890
He, K., Gou, X., Yuan, T., Lin, H., Asami, T., Yoshida, S., et al. (2007). BAK1 and BKK1 regulate brassinosteroid-dependent growth and brassinosteroid-independent cell-death pathways. Curr. Biol. 17, 1109-1115. doi: 10.1016/j.cub.2007.05.036

Heese, A., Hann, D. R., Gimenez-Ibanez, S., Jones, A. M., He, K., Li, J., et al. (2007). The receptor-like kinase SERK3/BAK1 is a central regulator of innate immunity in plants. Proc. Natl. Acad. Sci. U.S.A. 104, 12217-12222. doi: 10.1073/pnas.0705306104

Huang, J., Gu, M., Lai, Z., Fan, B., Shi, K., Zhou, Y.-H., et al. (2010). Functional analysis of the Arabidopsis PAL gene family in plant growth, development, and response to environmental stress. Plant Physiol. 153, 1526-1538. doi: 10.1104/pp.110.157370

Jones, J. D., and Dangl, J. L. (2006). The plant immune system. Nature 444, 323-329. doi: 10.1038/nature05286

Karlova, R., Boeren, S., Russinova, E., Aker, J., Vervoort, J., and de Vries, S. (2006). The Arabidopsis SOMATIC EMBRYOGENESIS RECEPTOR-LIKE KINASE1 protein complex includes BRASSINOSTEROID-INSENSITIVE1. Plant Cell 18, 626-638. doi: 10.1105/tpc.105.039412

Kemmerling, B., Schwedt, A., Rodriguez, P., Mazzotta, S., Frank, M., Qamar, S. A., et al. (2007). The BRI1-associated kinase 1, BAK1, has a brassinolideindependent role in plant cell-death control. Curr. Biol. 17, 1116-1122. doi: 10.1016/j.cub.2007.05.046

Knepper, C., Savory, E. A., and Day, B. (2011). The role of NDR1 in pathogen perception and plant defense signalling. Plant Signal. Behav. 6, 1114-1116. doi: $10.4161 /$ psb.6.8.15843

Li, J. (2010). Multi-tasking of somatic embryogenesis receptor-like protein kinases. Curr. Opin. Plant. Biol. 13, 509-514. doi: 10.1016/j.pbi.2010.09.004

Li, J., and Chory, J. (1997). A putative leucine-rich repeat receptor kinase involved in brassinosteroid signal transduction. Cell 90, 929-938. doi: 10.1016/S0092-8674(00)80357-8

Li, J., Wen, J., Lease, K. A., Doke, J. T., Tax, F. E., and Walker, J. C. (2002). BAK1, an Arabidopsis LRR receptor-like protein kinase, interacts with BRI1 and modulates brassinosteroid signalling. Cell 110, 213-222. doi: 10.1016/S0092-8674(02)00812-7

Li, L., Kim, P., Yu, L., Cai, G., Chen, S., Alfano, J. R., et al. (2016). Activation-dependent destruction of a co-receptor by a Pseudomonas syringae effector dampens plant immunity. Cell Host Microbe 20, 504-514. doi: 10.1016/j.chom.2016.09.007

Li, Y., Chen, L., Mu, J., and Zuo, J. (2013). LESION SIMULATING DISEASE1 interacts with catalases to regulate hypersensitive cell death in Arabidopsis. Plant Physiol. 163, 1059-1070. doi: 10.1104/pp.113.225805

Macho, A. P., and Zipfel, C. (2014). Plant PRRs and the activation of innate immune signalling. Mol. Cell 54, 263-272. doi: 10.1016/j.molcel.2014.03.028

Macho, A. P., Schwessinger, B., Ntoukakis, V., Brutus, A., Segonzac, C., Roy, S., et al. (2014). A bacterial tyrosine phosphatase inhibits plant pattern recognition receptor activation. Science 343, 1509. doi: 10.1126/science.1248849

Mauch-Mani, B., and Slusarenko, A. J. (1996). Production of salicylic acid precursors is a major function of phenylalanine ammonia-lyase in the resistance of Arabidopsis to Peronospora parasitica. Plant Cell 8, 203-212. doi: $10.1105 /$ tpc.8.2.203

Métraux, J.-P. (2002). Recent breakthroughs in the study of salicylic acid biosynthesis. Trends Plant Sci. 7, 332-334. doi: 10.1016/S1360-1385(02)0 2313-0

Meyers, B. C., Dickerman, A. W., Michelmore, R. W., Sivaramakrishnan, S., Sobral, B. W., and Young, N. D. (1999). Plant disease resistance genes encode members of an ancient and diverse protein family within the nucleotide-binding superfamily. Plant J. 20, 317-332. doi: 10.1046/j.1365-313X.1999.t01-1-0 0606.x

Nam, K. H., and Li, J. (2002). BRI1/BAK1, a receptor kinase pair mediating brassinosteroid signalling. Cell 110, 203-212. doi: 10.1016/S0092-8674(02) 00814-0

Nawkar, G. M., Maibam, P., Park, J. H., Sahi, V. P., Lee, S. Y., and Kang, C. H. (2013). UV-induced cell death in plants. Int. J. Mol. Sci. 14, 1608-1628. doi: 10.3390/ijms14011608

Nawrath, C., Heck, S., Parinthawong, N., and Métraux, J.-P. (2002). EDS5, an essential component of salicylic acid-dependent signalling for disease resistance in Arabidopsis, is a member of the MATE transporter family. Plant Cell 14, 275-286. doi: 10.1105/tpc.010376 
Nawrath, C., and Métraux, J. P. (1999). Salicylic acid induction-deficient mutants of Arabidopsis express PR-2 and PR-5 and accumulate high levels of camalexin after pathogen inoculation. Plant Cell 11, 1393-1404. doi: 10.2307/3870970

Pedmale, U. V., Huang, S.-S., Zander, M., Cole, B. J., Hetzel, J., Ljung, K., et al. (2016). Cryptochromes interact directly with PIFs to control plant growth in limiting blue light. Cell 164, 233-245. doi: 10.1016/j.cell.2015.12.018

Rasmussen, M. W., Roux, M., Petersen, M., and Mundy, J. (2012). MAP kinase cascades in Arabidopsis innate immunity. Front. Plant Sci. 3:169. doi: 10.3389/fpls.2012.00169

Rietz, S., Stamm, A., Malonek, S., Wagner, S., Becker, D., Medina-Escobar, N., et al. (2011). Different roles of Enhanced Disease Susceptibility1 (EDS1) bound to and dissociated from Phytoalexin Deficient4 (PAD4) in Arabidopsis immunity. New Phytol. 191, 107-119. doi: 10.1111/j.1469-8137.2011. 03675.x

Rogers, E. E., and Ausubel, F. M. (1997). Arabidopsis enhanced disease susceptibility mutants exhibit enhanced susceptibility to several bacterial pathogens and alterations in PR-1 gene expression. Plant Cell 9, 305-316. doi: $10.1105 /$ tpc.9.3.305

Roux, M., Schwessinger, B., Albrecht, C., Chinchilla, D., Jones, A., Holton, N., et al. (2011). The Arabidopsis leucine-rich repeat receptor-like kinases BAK1/SERK3 and BKK1/SERK4 are required for innate immunity to hemibiotrophic and biotrophic pathogens. Plant Cell 23, 2440-2455. doi: 10.1105/tpc.111.084301

Schmidt, E. D., Guzzo, F., Toonen, M. A., and de Vries, S. C. (1997). A leucine-rich repeat containing receptor-like kinase marks somatic plant cells competent to form embryos. Development 124, 2049-2062.

Schulze, B., Mentzel, T., Jehle, A. K., Mueller, K., Beeler, S., Boller, T., et al. (2010). Rapid heteromerization and phosphorylation of ligand-activated plant transmembrane receptors and their associated kinase BAK1. J. Biol. Chem. 285, 9444-9451. doi: 10.1074/jbc.M109.096842

Schwessinger, B., Roux, M., Kadota, Y., Ntoukakis, V., Sklenar, J., Jones, A., et al. (2011). Phosphorylation-dependent differential regulation of plant growth, cell death, and innate immunity by the regulatory receptor-like kinase BAK1. PLoS Genet. 7:e1002046. doi: 10.1371/journal.pgen.1002046

Serrano, M., Wang, B., Aryal, B., Garcion, C., Abou-Mansour, E., Heck, S., et al. (2013). Export of salicylic acid from the chloroplast requires the multidrug and toxin extrusion-like transporter EDS5. Plant Physiol. 162, 1815-1821. doi: 10.1104/pp.113.218156

Shan, L., He, P., Li, J., Heese, A., Peck, S. C., Nürnberger, T., et al. (2008). Bacterial effectors target the common signalling partner BAK1 to disrupt multiple MAMP receptor-signalling complexes and impede plant immunity. Cell Host Microbe 4, 17-27. doi: 10.1016/j.chom.2008.05.017

Shpak, E. D., McAbee, J. M., Pillitteri, L. J., and Torii, K. U. (2005). Stomatal patterning and differentiation by synergistic interactions of receptor kinases. Science 309, 290-293. doi: 10.1126/science.1109710

Szechyńska-Hebda, M., and Karpiński, S. (2013). Light intensity-dependent retrograde signalling in higher plants. J. Plant Physiol. 170, 1501-1516. doi: 10.1016/j.jplph.2013.06.005

Torres, M. A., Jones, J. D. G., and Dangl, J. L. (2006). Reactive oxygen species signalling in response to pathogens. Plant Physiol. 141, 373-378. doi: $10.1104 /$ pp.106.079467
Tsuda, K., Mine, A., Bethke, G., Igarashi, D., Botanga, C. J., Tsuda, Y., et al. (2013). Dual regulation of gene expression mediated by extended MAPK activation and salicylic acid contributes to robust innate immunity in Arabidopsis thaliana. PLoS Genet. 9:e1004015. doi: 10.1371/journal.pgen.1004015

Vlot, A. C., Dempsey, D. A., and Klessig, D. F. (2009). Salicylic acid, a multifaceted hormone to combat disease. Annu. Rev. Phytopathol. 47, 177-206. doi: 10.1146/annurev.phyto.050908.135202

Wang, Z., Meng, P., Zhang, X., Ren, D., and Yang, S. (2011). BON1 interacts with the protein kinases BIR1 and BAK1 in modulation of temperaturedependent plant growth and cell death in Arabidopsis. Plant J. 67, 1081-1093. doi: 10.1111/j.1365-313X.2011.04659.x

Wiermer, M., Feys, B. J., and Parker, J. E. (2005). Plant immunity: the EDS1 regulatory node. Curr. Opin. Plant. Biol. 8, 383-389. doi: $10.1016 /$ j.pbi.2005.05.010

Wildermuth, M. C., Dewdney, J., Wu, G., and Ausubel, F. M. (2001). Isochorismate synthase is required to synthesize salicylic acid for plant defence. Nature 414, 562-565. doi: 10.1038/35107108

Xiang, T., Zong, N., Zou, Y., Wu, Y., Zhang, J., Xing, W., et al. (2008). Pseudomonas syringae effector AvrPto blocks innate immunity by targeting receptor kinases. Curr. Biol. 18, 74-80. doi: 10.1016/j.cub.2007.12.020

Yamada, K., Yamashita-Yamada, M., Hirase, T., Fujiwara, T., Tsuda, K., Hiruma, K., et al. (2016). Danger peptide receptor signaling in plants ensures basal immunity upon pathogen-induced depletion of BAK1. EMBO J. 35, 46-61. doi: 10.15252/embj.201591807

Yang, S., Yang, H., Grisafi, P., Sanchatjate, S., Fink, G. R., Sun, Q., et al. (2006). The BON/CPN gene family represses cell death and promotes cell growth in Arabidopsis. Plant J. 45, 166-179. doi: 10.1111/j.1365-313X.2005.0 2585.x

Zhao, D.-Z., Wang, G.-F., Speal, B., and Ma, H. (2002). The EXCESS MICROSPOROCYTES1 gene encodes a putative leucine-rich repeat receptor protein kinase that controls somatic and reproductive cell fates in the Arabidopsis anther. Genes Dev. 16, 2021-2031. doi: 10.1101/gad.997902

Zhou, J., Wu, S., Chen, X., Liu, C., Sheen, J., Shan, L., et al. (2014). Pseudomonas syringae effector HopF2 suppresses Arabidopsis immunity by targeting BAK1. Plant J. 77, 235-245. doi: 10.1111/tpj.12381

Zipfel, C., Kunze, G., Chinchilla, D., Caniard, A., Jones, J. D., Boller, T., et al. (2006). Perception of the bacterial PAMP EF-Tu by the receptor EFR restricts Agrobacterium-mediated transformation. Cell 125, 749-760. doi: $10.1016 /$ j.cell.2006.03.037

Conflict of Interest Statement: The authors declare that the research was conducted in the absence of any commercial or financial relationships that could be construed as a potential conflict of interest.

Copyright (c) 2017 Gao, Wu, Du, Zhan, Sun, Zhao, Zhang, Li and He. This is an open-access article distributed under the terms of the Creative Commons Attribution License (CC BY). The use, distribution or reproduction in other forums is permitted, provided the original author(s) or licensor are credited and that the original publication in this journal is cited, in accordance with accepted academic practice. No use, distribution or reproduction is permitted which does not comply with these terms. 